\title{
CHARACTERIZATION OF SOIL WETTABILITY CHANGES OF A DIESEL-IMPACTED FIELD SOIL
}

\author{
Submitted by \\ MOSTAFA SAID \\ B.Sc., Arab Academy for Science \& Technology, Cairo, Egypt
}

\begin{abstract}
A thesis submitted to
The Faculty of Graduate Studies and Post Doctoral Affairs

in partial fulfillment of the requirements for the degree of

Masters of Applied Science

in Environmental Engineering

Department of Civil and Environmental Engineering

Carleton University

Ottawa, Ontario
\end{abstract}

(C) Mostafa Said 2010

The Masters of Applied Science in Environmental Engineering is a joint program with the University of Ottawa, administrated by the Ottawa-Carleton Institute for Environmental Engineering 


$\begin{array}{ll}\begin{array}{l}\text { Library and Archives } \\ \text { Canada }\end{array} & \begin{array}{l}\text { Bibliothèque et } \\ \text { Archives Canada }\end{array} \\ \begin{array}{l}\text { Published Heritage } \\ \text { Branch }\end{array} & \begin{array}{l}\text { Direction du } \\ \text { Patrimoine de lédition }\end{array} \\ \begin{array}{l}\text { 395 Wellington Street } \\ \text { Ottawa ON K1A ON4 } \\ \text { Canada }\end{array} & \begin{array}{l}\text { 395, rue Wellington } \\ \text { Ottawa ON K1A ON4 } \\ \text { Canada }\end{array}\end{array}$

Your file Votre référence

ISBN: 978-0-494-71560-4

Our file Notre référence

ISBN: 978-0-494-71560-4

NOTICE:

The author has granted a nonexclusive license allowing Library and Archives Canada to reproduce, publish, archive, preserve, conserve, communicate to the public by telecommunication or on the Internet, loan, distribute and sell theses worldwide, for commercial or noncommercial purposes, in microform, paper, electronic and/or any other formats.

The author retains copyright ownership and moral rights in this thesis. Neither the thesis nor substantial extracts from it may be printed or otherwise reproduced without the author's permission.
AVIS:

L'auteur a accordé une licence non exclusive permettant à la Bibliothèque et Archives Canada de reproduire, publier, archiver, sauvegarder, conserver, transmettre au public par télécommunication ou par l'Internet, prêter, distribuer et vendre des thèses partout dans le monde, à des fins commerciales ou autres, sur support microforme, papier, électronique et/ou autres formats.

L'auteur conserve la propriété du droit d'auteur et des droits moraux qui protège cette thèse. Ni la thèse ni des extraits substantiels de celle-ci ne doivent être imprimés ou autrement reproduits sans son autorisation.
In compliance with the Canadian Privacy Act some supporting forms may have been removed from this thesis.

While these forms may be included in the document page count, their removal does not represent any loss of content from the thesis.
Conformément à la loi canadienne sur la protection de la vie privée, quelques formulaires secondaires ont été enlevés de cette thèse.

Bien que ces formulaires aient inclus dans la pagination, il n'y aura aucun contenu manquant.

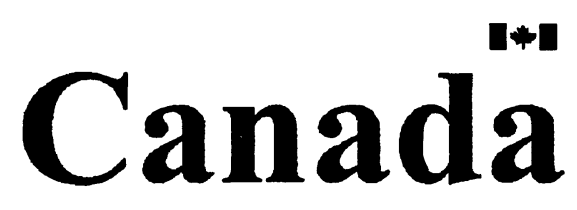




\section{ACKNOWLEDGEMENT}

The author would like to express his deepest and sincerest gratitude to his supervisor Professor Paul Van Geel, Chair of Department of Civil and Environmental Engineering. Professor Van Geel has been more than just a supervisor through the course of the research and in the preparation for this document. His time, efforts, and patience are highly appreciated. This work would not have been possible without the guidance and the help he provided.

The author would also like to thank the staff members at the Civil and Environmental Engineering Laboratory: Marie Tudoret, Stanley Conley, Pierre Trudel, and Jim Whitehorne, whom have helped throughout the research work.

The author would like also to thank his parents and family for their continuous support and encouragement, especially his Father Dr. Galal Said. 


\begin{abstract}
To date, most experimental research has focused on the migration and distribution of lab grade Non-Aqueous Phase Liquids (NAPLs) in water-wet quartz sand. However, this may not be the case at many industrial field sites where NAPLs are not found as single pure phases. NAPLs; often consist of many compounds, and the soil medium, may not be water-wet. This research assessed the wettability variations of soils collected at a diesel-impacted site. Series of wettability tests were conducted for soil samples collected at a former truck stop where leakage had occurred from underground storage tanks. Visual observation, imbibition rate tests, and a series of two-phase (water-diesel) capillary pressure-saturation $\left(P_{c^{-}} S\right)$ experiments were conducted on clean and on dieselimpacted soil samples. Results indicated wettability change comparing the clean versus diesel-impacted soil. Wettability was hypothesised to be altered due to the prolonged exposure to diesel plus the existence of additives.
\end{abstract}




\section{Table of Contents}

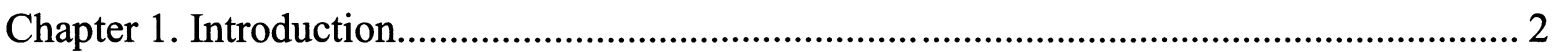

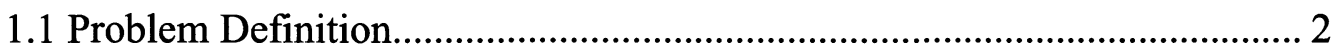

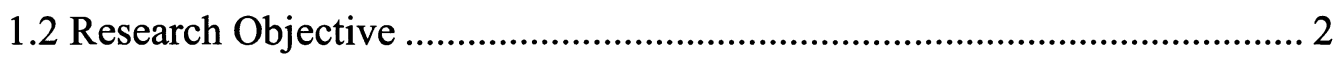

1.2.1. Scope

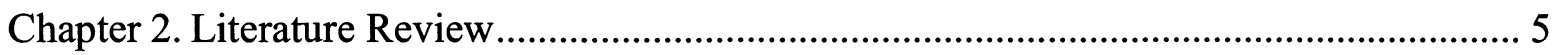

2.1 Wettability of Porous Media .................................................................. 5

2.2 Methods of Characterization.......................................................................... 7

2.2.1. Qualitative Methods................................................................................ 7

2.2.2. Quantitative Methods....................................................................... 9

2.3 Wettability Alteration Factors.................................................................... 17

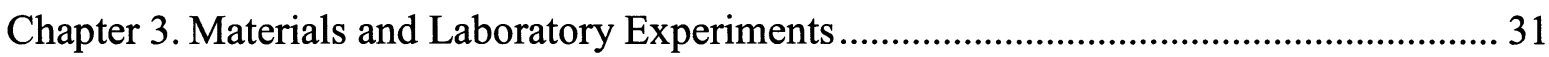

3.1 Soil and Fluid System Properties................................................................... 31

3.1.1. Soil medium properties ....................................................................... 32

3.1.2. Fluid Properties ................................................................................... 34

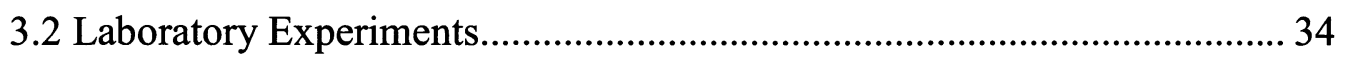

3.2.1. Visual Observation Experiments .......................................................... 34

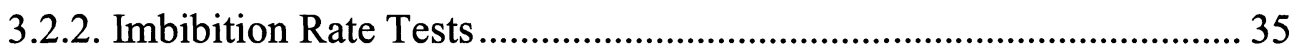

3.2.3. Capillary Pressure-Saturation $\left(P_{c}-S\right)$ Experiments ............................ 36

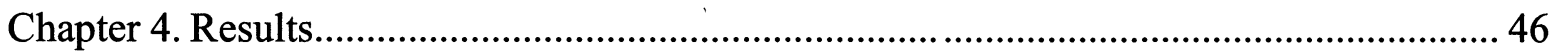

4.1 Soil Properties ......................................................................................... 46

4.2 Fluid Properties .................................................................................... 50

4.3 Visual Observation Results.......................................................................... 51

4.4 Imbibition Rate Results............................................................................. 53 


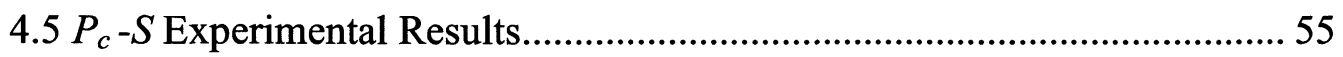

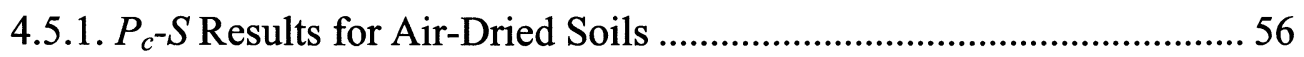

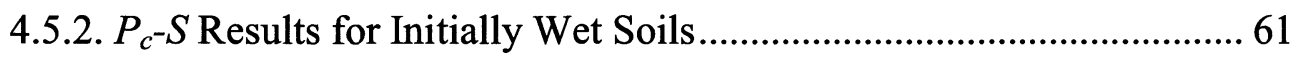

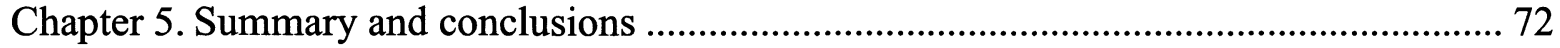

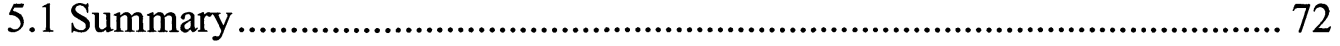

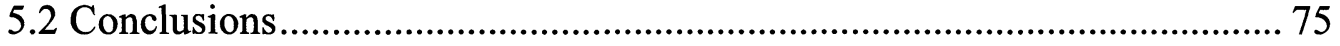

5.3 Recommendations for Future Work ....................................................... 76

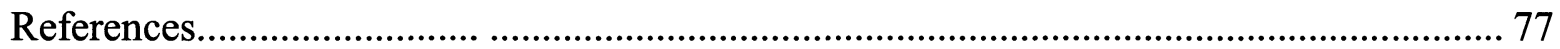




\section{LIST OF FIGURES}

Figure 2.1: Contact Angle Values of NAPL droplets on Solid Surface Immersed in Water

Phase. 6

Figure 2.2: Imbibition Rate Tests for Soil with Different Wetting Affinities. (Taken From

Powers and Tamblin, 1995) 9

Figure 2.3: Capillary Pressure-Saturation Relationship Indices (a) Amott-Harvey Method;

and (b) USBM Method. (Taken From Powers and Tamblin, 1995)..... 12

Figure 2.4: NAPL-Water $P_{c}-S$ Relationships with Varied OTS Fraction (a) Main Drainage Pathway; and (b) Main Wetting Pathway. (Taken From Bradford and Leij, 1995) 16

Figure 2.5: Measured Interfacial Tension Values with Varying pH Values. (Taken From

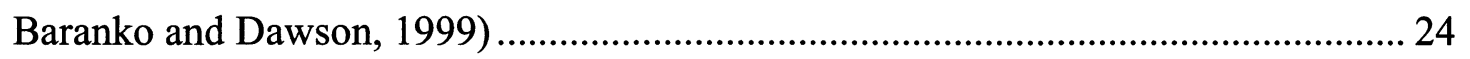

Figure 2.6: Measured Static, Advancing, and Receding Contact Angle Values with Varying pH Values. (Taken From Baranko and Dawson, 1999) ............................... 25

Figure 2.7: Receding PCE droplets on Quartz (Left) and Iron Oxide Plates (Right) Initially Immersed in Water at $\mathrm{pH}$ of 6.5 at DDA of 0.0027M. (Taken From Molnar, 2009) 26

Figure 3.1: Schematic Diagram of the Collected Soil Samples Location and the Diesel Tanks. 32

Figure 3.2: Water Imbibition Rate Test (a) At Time $(t)=0$ Minutes; and (b) At $(t)=100$

Minutes... 36

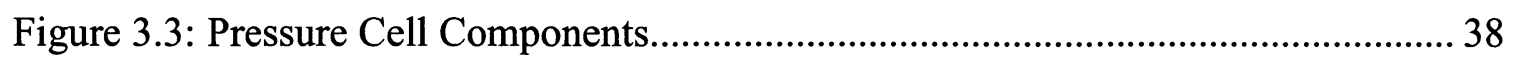

Figure 3.4: Schematic Diagram of Pressure Cell........................................................ 38

Figure 3.5: Top and Bottom Parts of Pressure Cell (Plan View).................................... 39 
Figure 3.6: Middle Part of Pressure Cell (Plan View)..................................................... 39

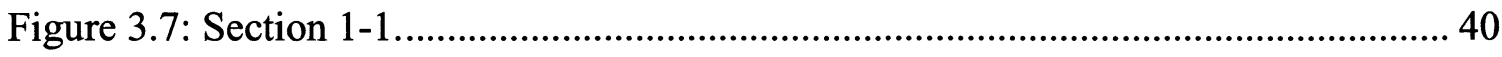

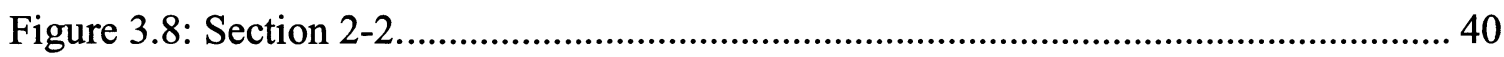

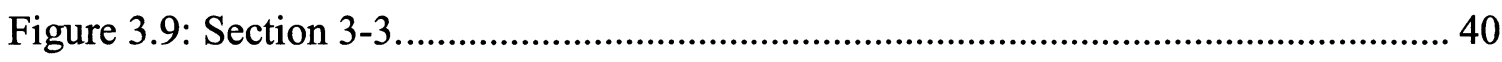

Figure 3.10: Air-Dried Soil Samples Used (Without Fines).............................................. 41

Figure 3.11: Initially Wet Soil Samples Used (With Fines)............................................ 44

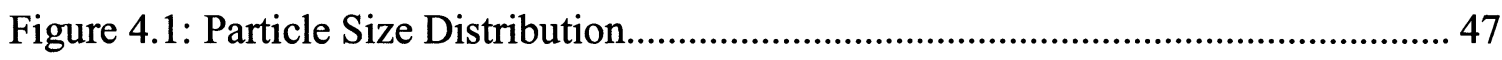

Figure 4.2: Different Wetting Behaviours observed for Clean (Left) and Air-Dried

Contaminated Soil (Right). ...................................................................................... 52

Figure 4.3: Water Imbibition Rate in Air-Dried Clean and Air-Dried Contaminated Soil

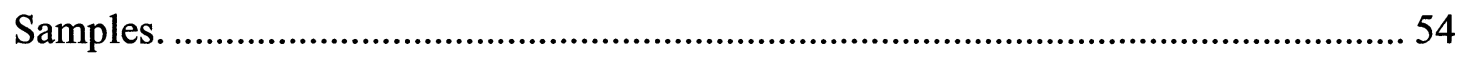

Figure 4.4: Diesel Imbibition Rate in Air-Dried Clean and Air-Dried Contaminated Soil

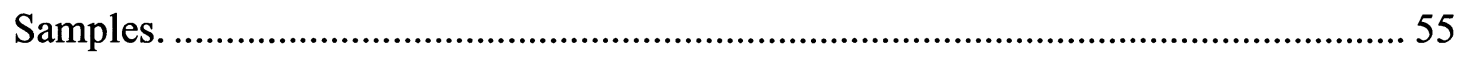

Figure 4.5: Main Drainage $P_{c}-S$ relationships of Air-Dried Clean and Air-Dried

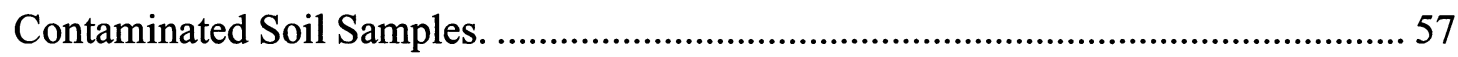

Figure 4.6: Main Wetting $P_{c}-S$ relationships of Air-Dried Clean and Air-Dried

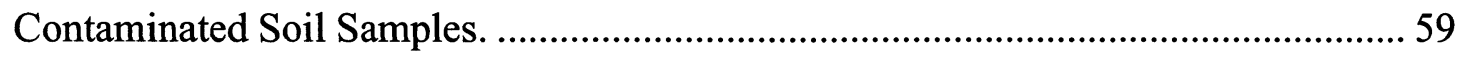

Figure 4.7: Main Drainage $P_{c}-S$ relationships of Air-Dried Clean and Initially Wet Clean

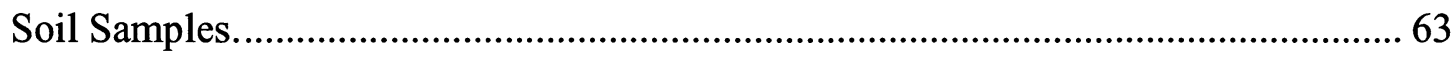

Figure 4.8: Main Wetting $P_{c}-S$ relationships of Air-Dried Clean and Initially Wet Clean

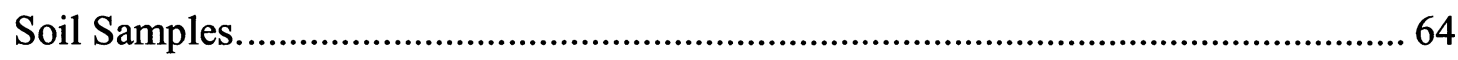

Figure 4.9: Main Drainage $P_{c}-S$ relationships of Initially Wet Clean and Initially Wet Contaminated Soil Samples. 66 
Figure 4.10: Main Wetting $P_{c}-S$ relationships of Initially Wet Clean and Initially Wet Contaminated Soil Samples.

Figure 4.11: Effects of Fractional Wettability on Different Soil Media. (Taken From Fatt

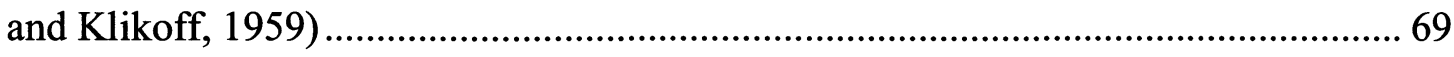

Figure 4.12: Effects of Treating the Fines Fraction on the $P_{c^{-}} S$ relationship. (Taken From

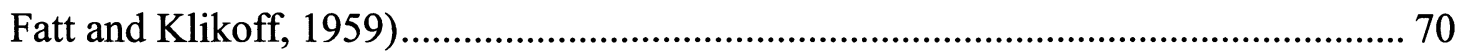




\section{LIST OF TABLES}

Table 2.1: Differences in USBM Values $\left(\mathrm{I}_{\mathrm{w}}\right)$ for Cores using Mineral Oil and Mineral Oil with 5\% Solution of Polar Compounds. (Taken From Donaldson and Crocker, 1980)

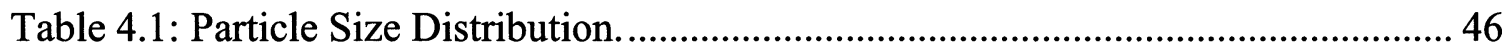

Table 4.2: Dry Density and Porosity Values. ............................................................. 47

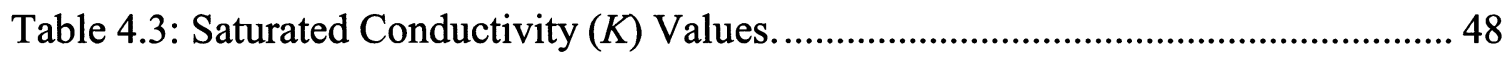

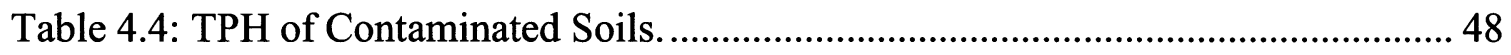

Table 4.5: Organic Content of Air-Dried Clean and Air-Dried Contaminated Soil

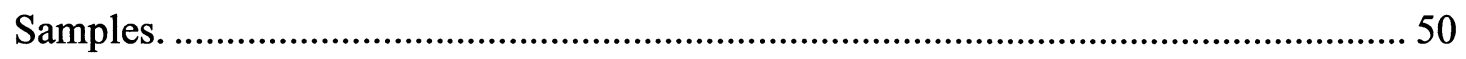

Table 4.6: Physical Characteristics of Fluids.......................................................... 51

Table 4.7: Parameters Resulted from $\mathrm{P}_{\mathrm{c}}-\mathrm{S}$ relationships Conducted for Air-Dried Clean

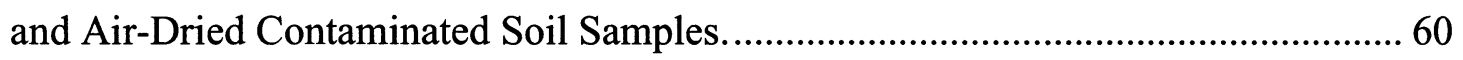

Table 4.8: Parameters Resulted from $\mathrm{P}_{\mathrm{c}}-\mathrm{S}$ relationships Conducted for Initially Wet Clean and Initially Wet Contaminated Soil Samples. 65 


\section{Chapter 1. INTRODUCTION}

\subsection{Problem Definition}

To date, most experimental research has focused on the migration and distribution of lab grade Non-Aqueous Phase Liquids (NAPLs) (e.g. heptane, trichloroethyene (TCE)) in clean water-wet quartz sand (e.g. Van Geel and Sykes, 1997; Gerhard and Kueper, 2003), which is water-wet at $\mathrm{pH}$ values greater than two (Anderson, 1986). In addition, most multiphase constitutive relationships and numerical models that simulate the distribution and remediation of subsurface soils are based on the assumption that water is the wetting fluid while NAPL is the non-wetting fluid (e.g. Parker et al., 1987). However, recent studies have noted the presence of intermediate- to NAPL-wet soils or $\mathrm{pH}$ dependant wettability in subsurface environments. The presence of such soils will affect our efforts to remediate industrial sites exposed to NAPLs (Powers et al., 1996). In addition to the presence of intermediate- and NAPL-wet soils, they have noted that the wettability of some subsurface soils can be altered; originally water-wet soils may become intermediate-wet or even NAPL-wet.

The potential for changes in wettability of the subsurface soil has been noted through a number of experimental studies (Harrold et al., 2001; Baranko and Dawson, 1999; Powers and Tamblin, 1995; and Ryder and Demond, 2008). Changes that occurred, according to previous studies, were due to a number of reasons: sorption, $\mathrm{pH}$ dependence, surface active agents, and contact order theory. As a result, constitutive relationships and numerical models that are based on the assumption that water is the wetting fluid while 
NAPL is the non-wetting fluid, have to be modified to take into account wettability variations.

Several methods were listed in the literature to evaluate the wettability of a certain porous medium. Some of these methods are qualitative, e.g. bottle test (Powers et al., 1996), and some are quantitative, e.g. capillary tests (Amott, 1959; Anderson, 1986) and contact angle measurements. Most of these methods were employed on clean water-wet quartz sand and lab grade NAPLs, but only recently have field soils and NAPLs been included within wettability assessment tests.

Wettability evaluation was assessed in a study by Powers et al. (1996), where clean quartz sand, lab grade (i.e. pure) NAPLs, and field NAPLs were used throughout the study. They noted that the wettability of the subsurface soil was altered due to the complex field NAPL mixtures while pure solvents did not have any impact on the wettability of the soil. Moreover, much lower recoveries were observed at sites where

complex NAPL mixtures exist (Powers et al., 1996). As a result, NAPLs with certain properties (e.g. high molecular weights, multi components, and weathered NAPLs) can affect the system's wettability and in turn affect remediation efficiencies in terms of lower recoveries.

\subsection{Research Objective}

The objective of the research is to investigate the wettability characteristics of field soils and NAPLs with a goal to better understand the impacts of soil wettability on the constitutive relationships and modelling approaches used to simulate the movement, distribution, and remediation of NAPLs at NAPL-impacted sites. 
As mentioned by Dwarakanath et al. (2002), further work is required to assess wettability issues at industrial field sites through the use of field soils and NAPLs in laboratory experiments and through developing/modifying constitutive relationships and numerical models that account for NAPL/soil wettability, which in turn will improve the selection and implementation of remedial technologies applied at NAPL-impacted sites.

Several previous studies, e.g. Bradford and Leij (1995), conducted a number of two-phase (water-NAPL) experiments and established capillary pressure-saturation $\left(P_{c^{-}} S\right)$ relations with "fractional wettability" soils (i.e. soils that contained a fraction of waterwet soil grains and a fraction of NAPL-wet soil grains). Through these studies, they observed that as the wettability changed from water-wet, to intermediate-wet, to NAPLwet, the $P_{c}-S$ relationship shifted downwards and generated negative capillary pressure values. These results show that higher water pressures are required, compared to ideal water-wet systems, in order to recover or remobilize the non-wetting phase as the wettability of the soil changes to NAPL-wet. They introduced a shifting parameter that adjusts the $P_{c}-S$ relationship, and in turn the relative permeability-saturation $\left(k_{r}-S\right)$ relationship, to account for wettability variations. However, these efforts have not been transferred yet to soils and NAPLs collected from NAPL-impacted industrial sites.

\subsubsection{Scope}

The scope of the research is to assess the wettability of a diesel-impacted field soil collected from a truck stop where leakage had occurred from underground storage tanks used to store diesel. The focus of the research on field NAPLs and soils will ensure relevance to real world conditions. 
To assess the addressed relations, a range of tests including visual observation tests, imbibition rate tests and capillary pressure-saturation $\left(P_{c}-S\right)$ experiments were conducted. Comparisons between clean field soil samples, clean meaning no evidence of the soil being in direct contact with NAPL (i.e. benchmark), and diesel-impacted soil samples, from the same geologic unit, were assessed to determine if the prolonged exposure to NAPL (i.e. diesel) altered the wettability characteristics of the soil. Buchner funnels were used to conduct the imbibition rate tests while pressure cells were used to evaluate the capillary pressure-saturation $\left(P_{c^{-}} S\right)$ relationships for the field soils. 


\section{Chapter 2. LITERATURE REVIEW}

\subsection{Wettability of Porous Media}

The wettability of a porous medium refers to the spreading of an aqueous phase on a solid surface, immersed in a second fluid (Anderson, 1986). The wetting fluid will spread over the soil surface, tend to coat the grain, and will exist in the smaller pores due to the capillary forces while the non-wetting fluid will reside in the large pores within the soil formation. Wettability is an essential phenomenon that has to be taken into consideration upon assessing the migration and addressing possible remediation alternatives of NAPLs in the subsurface. Wettability is typically assessed using the contact angle, $\theta$, which is quantified by Young's equation (Anderson, 1986):

$$
\cos \theta=\frac{\gamma_{\mathrm{ns}}-\gamma_{\mathrm{ws}}}{\gamma_{n w}}
$$

where $\theta$ is the contact angle; $\gamma_{\mathrm{ns}}$ is the interfacial tension between the NAPL-solid; $\gamma_{w s}$ is the interfacial tension between water-solid; $\gamma_{n w}$ is the interfacial tension between the NAPL-water. Figure 2.1 shows contact angle values measured for the NAPL phase on the soil surface submersed in water. Contact angle values less than, measured through the water phase, $70^{\circ}$ indicate water wetting conditions apply, while $\theta>110^{\circ}$ indicated NAPL

wetting conditions apply. Contact angle values between $70^{\circ}$ and $110^{\circ}$ indicate neutral wetting conditions (Anderson, 1986). 


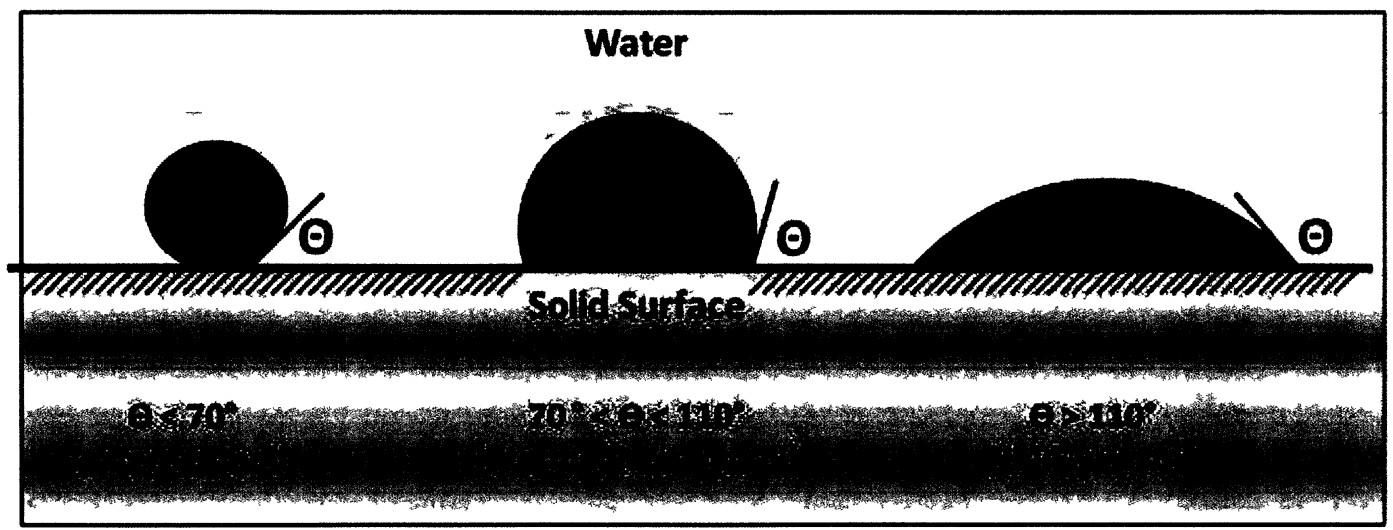

Figure 2.1: Contact Angle Values of NAPL droplets on Solid Surface Immersed in Water Phase.

Donaldson (2008) classified reservoirs into two main categories: silicate reservoirs and carbonate reservoirs. Silicate based reservoirs range from neutral to waterwet conditions and have a net negative surface charge which does not favour the attraction of positively charged polar compounds that may exist within the NAPL. Carbonate reservoirs may range from neutral to NAPL-wet and have a net positive charge as they have a basic surface and favour the attraction of polar compounds (Donaldson, 2008).

Most of the experimental research published to date is based on the assumption that water-wet conditions apply. However, recent studies and environmental practitioners have noted the presence of intermediate- to NAPL-wet soils. The presence of such soils will impact the migration and distribution of NAPL in the subsurface and the NAPL will no longer exist only within the large pore bodies. The distribution of NAPL in the subsurface is often referred to as the source zone architecture. Changes in the source zone architecture due to wettability variations may result in a greater residual NAPL saturation and may impact the efficiency of different remedial technologies. 
In the following section, potential factors that may lead to wettability alteration and methods of characterizing of wettability will be addressed.

\subsection{Methods of Characterization}

Several methods have been proposed in the literature to evaluate/characterize the wettability of a given soil medium. Some of these methods are qualitative methods; which gives only an indication of the soil's wettability, e.g. bottle test (Powers et al., 1996) while some are quantitative methods, e.g. contact angle measurement, capillary tests (Amott, 1959; Anderson, 1986). Different methods were listed in literature which will be summarized in this section.

\subsubsection{Qualitative Methods}

Qualitative methods are based on the observation of the behaviour of a porous medium upon the interaction with a certain fluid phase (Anderson, 1986). Moreover, these methods cannot be used to find an absolute value of wettability only an indication of the wettability is assessed.

\subsection{1.a. Bottle Test}

The idea behind the bottle test is the exposure of wet soil medium to a NAPL phase in small glass vials followed by the visual observation of the distribution of the NAPL. This technique was briefly described by Powers et al. (1996) in which field soil samples were collected and qualitative bottle test measurements were assessed.

The procedure developed for the bottle test is the addition of $10-20 \mathrm{~g}$ of soil medium in a screw cap glass vial; addition of water and allowing 24 hours for equilibrium; gravity drainage of the excess water from the sand; adding $5 \mathrm{~mL}$ of NAPL 
and leaving for another 24 hours. After the 24 hours period, excess water is added and the glass vials are gently shaken in the horizontal direction. Visual observation of the distribution of the phases is then used to infer the wettability of the porous medium tested. If after shaking the glass vials NAPL was separated from the porous medium and held on the top of the excess water, then this soil is said to be water-wet.

This bottle test procedure was modified where soil samples were initially exposed to NAPL and then the addition of the aqueous phase. The same above procedures are followed except the initial exposure is to NAPL and then the addition of aqueous phase.

\subsection{1.b. Imbibition Rate Test}

An alternative means of qualitatively addressing wetting conditions of a certain porous medium is to measure the water imbibed spontaneously into the soil (Anderson, 1986). The main advantage of the imbibition rate test is it provides a quick indication of the wettability of the soil medium without the need of complicated instruments and calculations. The rate and amount of water which will imbibe into the soil medium is recorded with respect to time. Water-wet soil will draw water with a faster rate and by a greater amount than intermediate- and NAPL-wet soils. Figure 2.5 presents imbibition rate tests for soils with different wetting affinities.

Kyte et al. (1961) modified the imbibition rate test for addressing wettability in reservoir conditions. In this modified test, cores are to be submerged in brine and then the amount and rate of brine that is replaced with NAPL is recorded with respect to time. The core is known to be water-wet, if large volumes of brine were imbibed into the core with a high rate. Consequently, if a lower rate and volume of NAPL replacement occurred, then the core is said to have less water-wet conditions. 


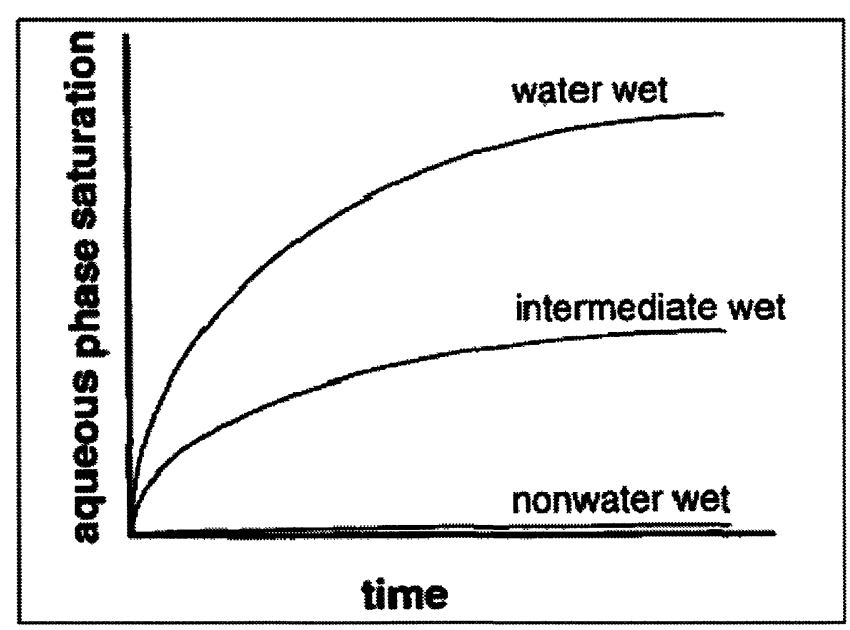

Figure 2.2: Imbibition Rate Tests for Soil with Different Wetting Affinities. (Taken From Powers and Tamblin, 1995)

\subsection{1.c. Visual Observation}

The visual observation is done in a similar way as the contact angle measurement but without any complicated techniques or methods in order to measure the formed contact angle; just the observation of the behaviour of the introduced fluid is examined. Visual observation method is conducted by the introduction of a static drop of a certain fluid phase onto the soil surface. The interaction of the introduced fluid and the porous medium is then examined. If a water droplet was to be introduced to a water-wet soil medium it will be drawn into the soil immediately as the soil favours the wetting of water than to be covered with air. On the other hand, if a water droplet was introduced to a NAPL-wet soil medium, water will stay as a droplet form on the soil surface and will require a higher pressure in order to be drawn into the soil.

\subsubsection{Quantitative Methods}

Many quantitative wettability tests have been cited in literature where an approximate value for quantifying the wettability of a porous medium can be obtained. 
Anderson (1986) reviewed different methods of quantifying the wettability of a porous medium: contact angle measurement, Amott-Harvey test, and USBM method.

\subsection{2.a. Contact Angle Measurement}

The contact angle measurement is considered to be the most common method used for the wettability measurement for a homogenous flat solid surface with the same mineralogy as the soil. There are few mentioned techniques in the literature in order to assess the contact angle value (e.g. sessile drop method, tilting plate method, tensiometric method, capillary rise method, and cylinder method) (Anderson, 1986). The most generally used technique is the sessile drop method which is the introduction of a sessile

drop of a certain fluid phase, on a solid surface initially immersed in another fluid phase. A contact angle is formed along the interface of the existing fluids and the solid surface which is function of the interfacial tension of the existing fluids and the solid surface. If a NAPL droplet was dropped onto a soil surface initially immersed in water, a contact angle is formed along the interface of the fluids.

As mentioned earlier, contact angle measurement is to be considered the best among quantitative methods but only upon the usage of pure fluid pair and flat homogenous surfaces. Quartz sand slides are always used for the contact angle measurement as most of the subsurface soils are known to be composed primarily of quartz (Anderson, 1986). The existence of any other compounds or additives (e.g. surfactants) in the fluid pairs or surface roughness may require additional time for equilibrium or even cause a significant error during measurement (Anderson, 1986). 


\subsection{2.b. Capillary Pressure - Saturation Relationship Indices}

Amott-Harvey and USBM indices can be calculated from the capillary pressuresaturation relationship, however these indices are not complete or sufficient in order to assess the wettability. $P_{c}-S$ relationship indices can be correlated together with the contact angle measurement and can give a strong characterization of the soil sample of concern. Amott-Harvey test depends mainly on the saturation at zero capillary pressure along the wetting pathway while USBM compares the work required for a certain fluid to displace the other as it all depends on the surface free energy. Less energy is exerted by the wetting fluid in order to wet a surface during the displacement of the other existing nonwetting fluid (Adamson, 1997). 


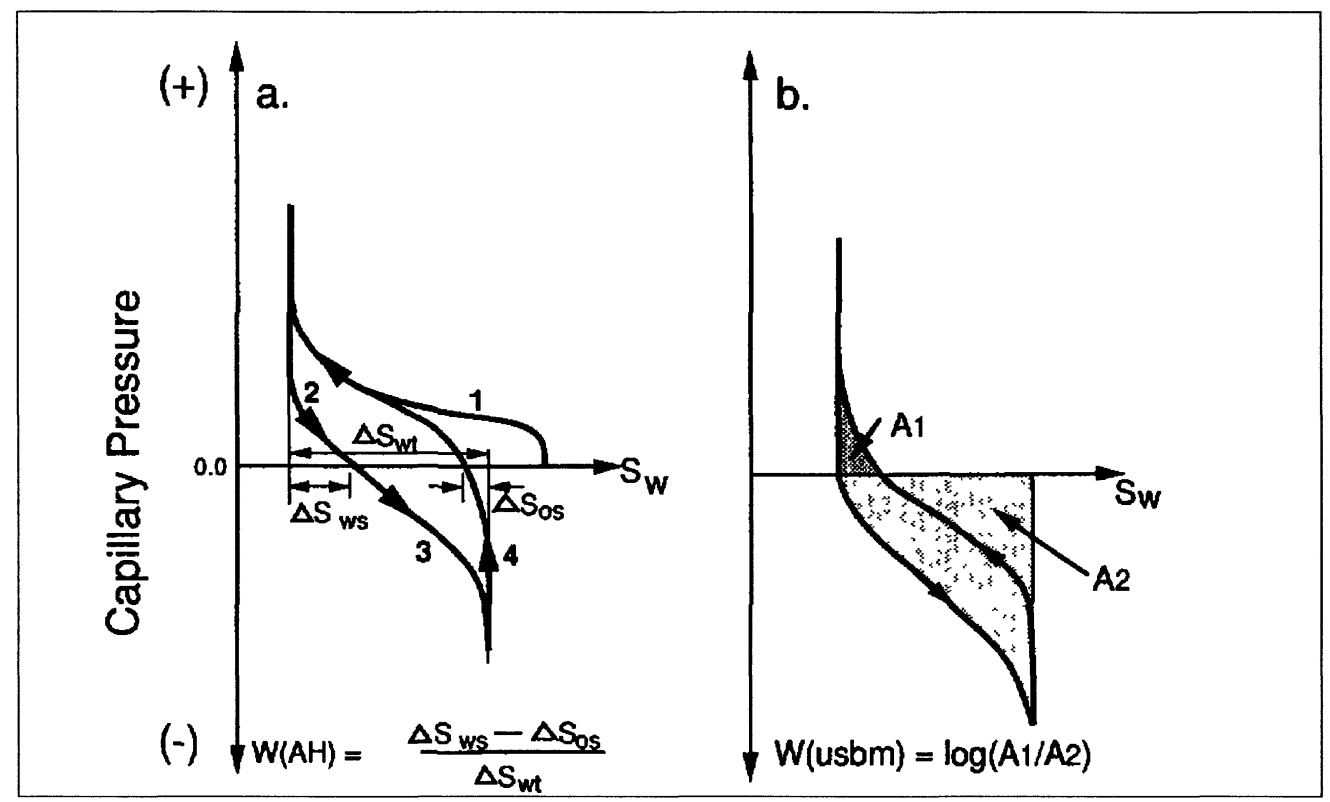

Figure 2.3: Capillary Pressure-Saturation Relationship Indices (a) Amott-Harvey Method; and (b) USBM Method. (Taken From Powers and Tamblin, 1995)

Figure 2.6 presents the capillary pressure-saturation relationship and the accompanied wettability indices which are calculated from the relationship. The curve marked 1 refers to the primary drainage; curve 2 refers to the spontaneous imbibition; curve 3 refers to the forced imbibition; while curve 4 refers to the secondary drainage (Powers and Tamblin, 1995). According to Figure 2.6, Amott-Harvey $\mathrm{W}_{(A H)}$ indices of $\left(0.3 \leq W_{a h} \leq 1\right)$ refer to water-wet media, $\left(-0.3 \leq \mathrm{W}_{a h} \leq 0.3\right)$ refer to intermediate-wet, and $\left(-1 \leq W_{a h} \leq-0.3\right)$ refer to NAPL-wet. USBM wettability index $W_{(u s b m)}$ with positive values refer to water-wet media while negative values refer to NAPL-wet media (Powers et al., 1996). 


\subsection{2.c. Capillary Pressure - Saturation Relationship}

The capillary pressure-saturation relationship is the relation between the capillary pressure induced on the surface or interface between two existing fluids and the volume (expressed as saturation) of the fluid of concern stored in the porous medium. The saturation of a fluid is the ratio between the volume of the pore volume filled with the fluid and the total pore volume. Capillary pressure-saturation relationship is a function of soil's wettability, soil medium pore structure and initial saturation (Anderson, 1987).

In the presence of two immiscible fluids, the capillary pressure along the interface is equal to the pressure of the least wetting fluid minus the pressure of the wetting fluid. In the presence of two fluids, the pressure at the fluid-fluid interface within the capillary tube can be calculated by the Laplace equation (Adamson, 1997):

$$
P_{c}=P_{n w}-P_{w}=(2 o \cos \Theta / r)
$$

where $P_{c}$ is the capillary pressure along the interface (wetting/non-wetting); $P_{n w}$ is the pressure on the non wetting phase; $P_{w}$ is the pressure on the wetting phase; $\sigma$ is the interfacial tension along the interface between the wetting and the non-wetting phase, $\Theta$ is the contact angle measured through the wetting phase; and $r$ is the radius of the capillary tube.

As observed in the previous equation, the pore radius is inversely proportional with the capillary pressure along the interface. As the pore radius increases, lower capillary pressure is required for the non-wetting phase to replace the wetting phase. Larger pores are drained first and filled with the non-wetting phase and then the smaller pores (higher capillary pressures needed for a smaller pore radius than a larger pore 
radius). The capillary pressure is a function of both the interfacial tension and the contact angle.

The following parts will be the discussion of capillary pressure-saturation relationships for water-wet media, and for fractionally wet media for which different fractions of soil grains were rendered NAPL-wet using octadecyltricholorosilane (OTS).

Most of the experimental research has focused on determining the capillary pressure-saturation relationship for strongly water-wet media. The term fractional wettability was then introduced to reflect a medium that contains water-wet and intermediate- or NAPL-wet fractions. The occurrence of fractionally or mixed wettability scenarios in the field were attributed to several reasons such as: adsorption of polar compounds or the deposition of organic material (Bradford and Leij, 1995).

Bradford and Leij (1995) presented results of two- and three-phase capillary pressure-saturation data for fractional wettability media. Fractional wettability media was formed by mixing quartz sand with the desired fraction of OTS treated quartz sand. The OTS treated sand was obtained by adding the sand to a five percent solution of OTS in ethanol. The solution was shaken for 5-hours and then the soil was air-dried. Deionized water and Soltrol 220 oil were used in their work. Results included the resultant $P_{c}-S$ curves for air-NAPL, air-water, and NAPL-water systems containing 0 percent, 25 percent, 50 percent, and 100 percent OTS treated media.

In air-water systems, drainage pathway results with 0,25 , and 50 percent media had a similar profile, while the 75 and 100 percent media had another similar profile. Lower $P_{c}$ values were observed for soils with greater fractions of OTS treated sand, upon comparing $P_{c}$ values at a given saturation for all of the soil specimens. This indicates that 
the water will be displaced more easily from the fractionally wet soil as the hydrophobic fraction increased. The hydrophobic sand favours to be coated with air rather than to be wet by water in air-water systems, and on the same basis, favour NAPL wetting in NAPL-water systems. The same behaviour was observed for the wetting pathways; also lower $P_{c}$ values were observed as the OTS treated sand fraction increased. As the capillary pressures decrease and become negative, positive water or wetting fluid pressure is needed to return the system to $100 \%$ saturation.

In air-NAPL systems, the $P_{c}-S$ curves were not influenced by the varied OTS treated sand fractions. It was indicated that Soltrol strongly wet the OTS treated sand as well as the untreated sand in comparison to air.

In NAPL-water systems, results for the drainage pathway indicated a decrease in the NAPL-water capillary pressure as the OTS treated sand fraction increased in the soil medium where less work was required for NAPL to replace water. Figure 2.7 presents the variation in the OTS fraction within the soil sample. The same behaviour was observed for the wetting pathways where $P_{c}$ values tend to decrease as the OTS treated sand fraction increased in the soil medium. The 75 and 100 percent OTS sand media resulted in negative $P_{c}$ values at approximate 30 percent of actual saturation which resulted in more water or wetting fluid pressure in order to get a full wetting pathway. That area of forced imbibition, above the wetting pathway and zero $P_{c}$ value, expanded as the OTS sand fraction increased. 


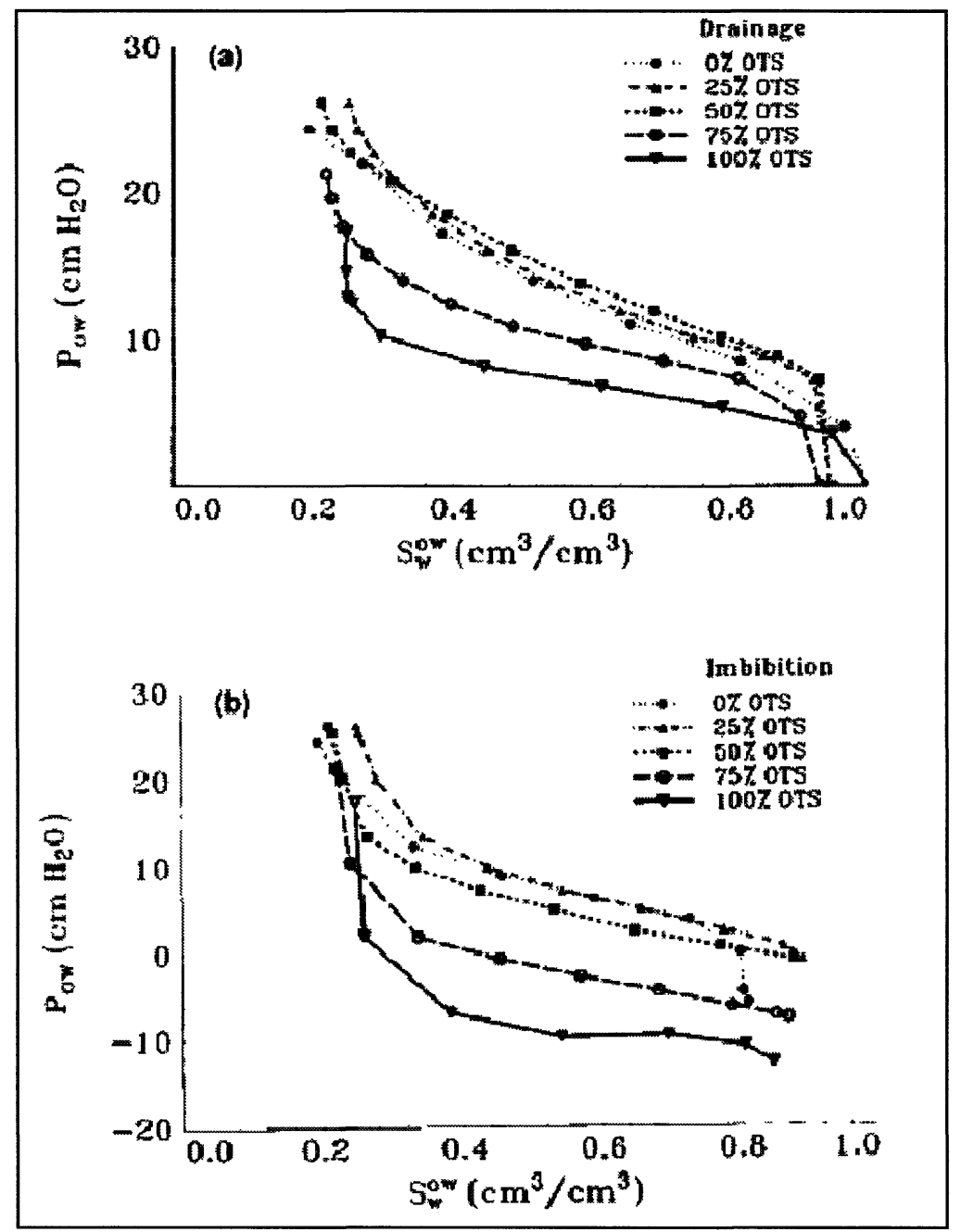

Figure 2.4: NAPL-Water $\boldsymbol{P}_{c}-\boldsymbol{S}$ Relationships with Varied OTS Fraction (a) Main

\section{Drainage Pathway; and (b) Main Wetting Pathway. (Taken From}

\section{Bradford and Leij, 1995)}

Powers and Tamblin (1995) assessed wetting conditions for soil minerals after exposure to synthetic gasoline. One of the techniques for measuring wettability was the capillary pressure-saturation relationship. Differences were observed between the two relations; quartz sand and isooctane as a control, and quartz sand exposed to isooctane containing one of four different additives. The most significant differences were observed after the exposure of quartz sand to isooctane with dodecylamine (DDA) and polybutene 
amine (PBA) compounds with concentrations of 500 parts per million (ppm) and $<0.22$ percent (weight basis) respectively. Larger areas were observed below the zero capillary pressure value and the wetting pathways for the isooctane with an additive. This indicates the need of forced imbibition through the system to displace the existing NAPL inside the soil with the aid of positive water pressure.

\subsection{Wettability Alteration Factors}

The migration and distribution of NAPLs in the subsurface depends on its capillary pressure and relative permeability, both of which are functions of soil medium's wettability and interfacial tension between water and the NAPL of concern (Dwarakanath et al., 2002). A better understanding of the factors influencing wettability alteration should be considered to ensure relevance of experiments to real world conditions.

A concept that is widely mentioned and assumed in the literature and by multiphase flow models is that soils are water-wet. This conceptual model was then attributed to the fact that most of the experimental work published to date used lab grade NAPLs and clean water-wet quartz sands. However, researchers and practitioners now recognise that these ideal conditions may not adequately represent field conditions. Field NAPLs may undergo certain processes that affect its characteristics. Some researchers acknowledge that some of the NAPLs are non-wetting relative to water in the subsurface, while wetting relative to air (Dwarakanath et al., 2002). Other researchers (e.g. Powers et al., 1996) state that laboratory grade NAPLs without impurities or surface active agents, have high interfacial tensions with respect to water, but upon the addition of surface active agents, which may be the case in the field, these values may be totally lower and as a result lead to the spreading of those NAPLs on the water surface. Most of the studies 
which addressed wetting conditions of porous media, stated that the outer surface of the porous medium prevails in assessing the wettability for the system and that the existence of any adsorbed polar constituents onto the surface will alter the system's wettability. This sorbed layer is due to the spreading of the polar constituents onto the outer surface of the soil grain (Morrow, 1990). Several other factors mentioned in literature relate the NAPL composition to wettability alteration. Some factors known to alter the soil's wettability include high molecular weight compounds within NAPLs, high equivalent alkane carbon number, and the multicomponent nature of NAPLs. Asphalteneous molecules, which are hydrogenated into polycyclic aromatic or hydroaromatic hydrocarbon groups containing nitrogen, sulfur, and oxygen, are known to affect the system's wettability by depositing of the asphaltenes onto the soil grain surface, making it more NAPL-wet (Morrow, 1990). Another contribution for wettability alteration is the existence of high organic carbon content within soils in the subsurface which will tend to decrease the soil's affinity to water and enhances the deposition of volatile components after oil spills.

Following are some of the environmental practitioners' findings of issues contributing to subsurface wettability alteration.

\section{High Molecular Weight NAPLs}

Dwarakanath et al. (2002) presented interfacial tension values and capillary pressure-saturation experiments for NAPLs recovered from the field and compared these values to lab grade NAPLs. Results showed lower interfacial tension values for field NAPLs than that of the lab grade NAPLs, consequently, positive spreading coefficients were obtained. It was emphasized that NAPLs with high molecular weights and the 
presence of surface active agents contribute to the wettability alteration of certain soil media by coating the soil outer surface.

\section{Additives}

Powers and Tamblin (1995) undertook an experimental investigation to determine the wetting conditions of soil after exposure to synthetic gasoline. Three different ways of assessing the soil's wettability were undertaken; water-NAPL contact angles, air-water imbibition rate tests, and water-NAPL capillary pressure-saturation relationships. Wettability tests were assessed for pure isooctane as a base case on quartz sand and with the addition of four compounds, which are considered as typical additives. The soil's wettability varied after exposure to additives into intermediate-wet to NAPL-wet conditions. Results showed that the most significant wettability alteration to NAPL-wet conditions was after the exposure of soil to dodecylamine (DDA) and polybutene amine (PBA) with concentrations of 500 parts per million $(\mathrm{ppm})$ and $<0.22$ percent (weight basis) respectively. These concentrations fall within the expected range of additives to gasoline. It was emphasized that the soil's wettability was altered due to the sorption of these additives to the mineral outer surface resulting in coating the soil surface. Neat solvents had no effect on the system`s wettability as no impurities and no surface active agents exist.

The presence of this surface film of additives or surfactants which coat the soil outer surface induce potential changes to soil or rock properties. This physically and/or chemically sorbed layer in some cases can be resistible and cannot be broken upon cleaning or heating the soil. The degree or the magnitude of this formed layer depends mainly on the type of soil mineral, NAPL composition, and the subsurface environment. 


\section{Contact Order Theory}

Ryder and Demond (2008) showed how the contact history of water and NAPLs can affect the wettability for a wide range of materials. Wettability was assessed using bottle tests and contact angle measurements. NAPL used throughout the study was perchloroethylene (PCE), whereas, deionized water with $0.01 \mathrm{M} \mathrm{NaCl}$ was used as the aqueous phase. Materials ranged from minerals to carbonaceous materials. The bottle test experiment was done by immersing the material tested in either PCE or aqueous phase and then the soil was left for 24 hours to equilibrate. After equilibrium time was achieved any excess fluid was drained and the second fluid was introduced and distribution between the two fluids was assessed after another 24 hours. Bottle test results were presented in two classifications: initially immersed in water and then contacted with PCE versus initially immersed in PCE and then contacted with water. All the materials tested for bottle tests in which the medium was initially immersed in water resulted in water-wet media including materials with high organic carbon content, which are cited as waterrepellent when first immersed in water. Results varied from water-wet to intermediatewet to NAPL-wet for materials initially immersed in PCE and then placed in contact with water. For water-wet soils, a distinct horizon between water and the denser PCE was observed. PCE can be seen within the pores of intermediate-wet materials. For the NAPL-wet media, PCE was completely within the soil media. The second test was the contact angle measurement where PCE-water (solid initially immersed in water) and water-PCE (solid initially immersed in PCE) contact angle values were measured. Contact angles were clearly dependant on the contact order of fluids; contact angle values 
differed with the variation of the first contacted fluid. The greatest hysteresis occurred in carbonaceous materials followed by a wide range of minerals.

The concept of wettability hysteresis was addressed by Ryder and Demond (2008) and a contact order theory was introduced and discussed through series of tests. Based on the study findings, contact order theory was hypothesised to be included within the potential factors known to induce wettability alteration. It was hypothesised by Ryder and Demond (2008) that the saturated zone can be considered as a water-wet media due to the continuous and direct contact of water to soil grains and the absence of organic matter, while, the vadose (unsaturated) zone can be considered as NAPL-wet as the degree of saturation is always less than unity. Hence, a greater chance of prolonged exposure of soil media in the unsaturated zone to NAPL and consequently, based on the contact history theory, its wettability can be altered into NAPL-wet. However, there is no conclusive research or findings that have been obtained which can contribute to the latter conclusion.

\section{Polar Compounds (Asphaltenes)}

Polar compounds which are known as asphaletenes are the products of the dilution of many crude oils after being mixed with low molecular weight alkanes (e.g. hexane, pentane) (Donaldson, 2008).

Donaldson and Crocker (1980) undertook a wettability investigation on two sets of Berea sandstone cores. The first set was examined using mineral oil and the second set was examined using mineral oil mixed with $5 \%$ solution of polar compounds. Wettability of the berea sandstone was measured with eight crude oils using the USBM (U.S. Bureau of Mines) wettability index (Anderson, 1986). Refer to section 2.3.2.b for more details on the capillary pressure indices Amott-Harvey and USBM methods. The first set of 
experiments, using mineral oil, indicated water-wet conditions based on the USBM index average value of 0.8 . The second set, cores were cleaned with toluene and then with steam and the same test procedure was undertaken but with the use of mineral oil mixed with $5 \%$ solution of polar compounds. Potential changes occurred compared to the first set where just mineral oil was used. The average USBM value decreased indicating a shift towards intermediate-wet to NAPL-wet conditions. Table 2.1 presents the USBM values calculated for the eight crude oils tested. It was hypothesized that the polar compounds were adsorbed onto the rock surface altering its wetting characteristics through the diffusion of asphaltene from the oil to the water films surrounding soil grains. Physical and/or chemical sorption of asphaltenes caused the alteration of the rock surface's (soil medium's) wettability from originally water-wet to NAPL-wet.

Table 2.1: Differences in USBM Values $\left(I_{w}\right)$ for Cores using Mineral Oil and Mineral Oil with 5\% Solution of Polar Compounds. (Taken From Donaldson and Crocker, 1980)

\begin{tabular}{|c|c|c|}
\hline Oil & $\begin{array}{c}\mathbf{I}_{\mathbf{w}} \text { of Core with } \\
\text { Mineral Oil }\end{array}$ & $\begin{array}{c}\mathbf{I}_{\mathrm{w}} \text { of Core with 5\% } \\
\text { Polar with Mineral Oil }\end{array}$ \\
\hline 1 & 0.773 & 0.450 \\
\hline 2 & 0.821 & 0.454 \\
\hline 3 & 0.817 & 0.410 \\
\hline 4 & 0.799 & 0.286 \\
\hline 5 & 0.773 & 0.150 \\
\hline 6 & 0.799 & 0.145 \\
\hline 7 & 0.817 & 0.118 \\
\hline 8 & 0.821 & $\mathbf{- 0 . 0 9 4}$ \\
\hline
\end{tabular}




\section{Oxidation Process}

Many studies have mentioned that oxidation of soil and reservoir cores after recovery, contribute to the alteration of its wettability. Anderson (1986) mentioned that crude oil components can be highly oxidized, upon the interaction of the core with surface air, causing the loss of light end hydrocarbons within crude oil and the deposition of polar compounds (e.g. surfactants) onto the surface, causing the alteration of its wettability.

Also Treiber et al. (1972) evaluated the wettability of rock cores from 50 oil producing reservoirs and found that contact angle values were extremely dependant on the surrounding environment during measurement. In the study, crude oil contact angle measurements resulted in water-wet media under anaerobic conditions, whereas, it resulted in oil-wet media after the aeration process.

\section{pH dependant wettability}

Baranko and Dawson (1999) showed the effect of the aqueous phase $\mathrm{pH}$ on the wettability of quartz sand and how it can dramatically affect its wetting conditions. Coal tar and water were used as the fluid pair throughout the study. Wettability tests included coal tar-water interfacial tension measurements and contact angle measurements. Measurements were recorded at various aqueous phase $\mathrm{pH}$ and constant ionic strength. Figure 2.2 presents coal tar-water interfacial tension with varied aqueous phase $\mathrm{pH}$. At low and neutral $\mathrm{pH}$, no marked variations were observed to occur in coal tar-water interfacial tension values; however, at high $\mathrm{pH}$ values the interfacial tension started to decrease gradually. A significant decrease in the coal tar-water interfacial tension was observed with the increase of the aqueous phase $\mathrm{pH}$. Contact angles (static, advancing, 
and receding) as function of aqueous phase $\mathrm{pH}$ are presented in Figure 3. Advancing and static contact angles exhibited no variations to occur along the different $\mathrm{pH}$ values, whereas, receding contact angles were high at low $\mathrm{pH}$ and started to decrease at neutral $\mathrm{pH}$, recording lower values at high $\mathrm{pH}$.

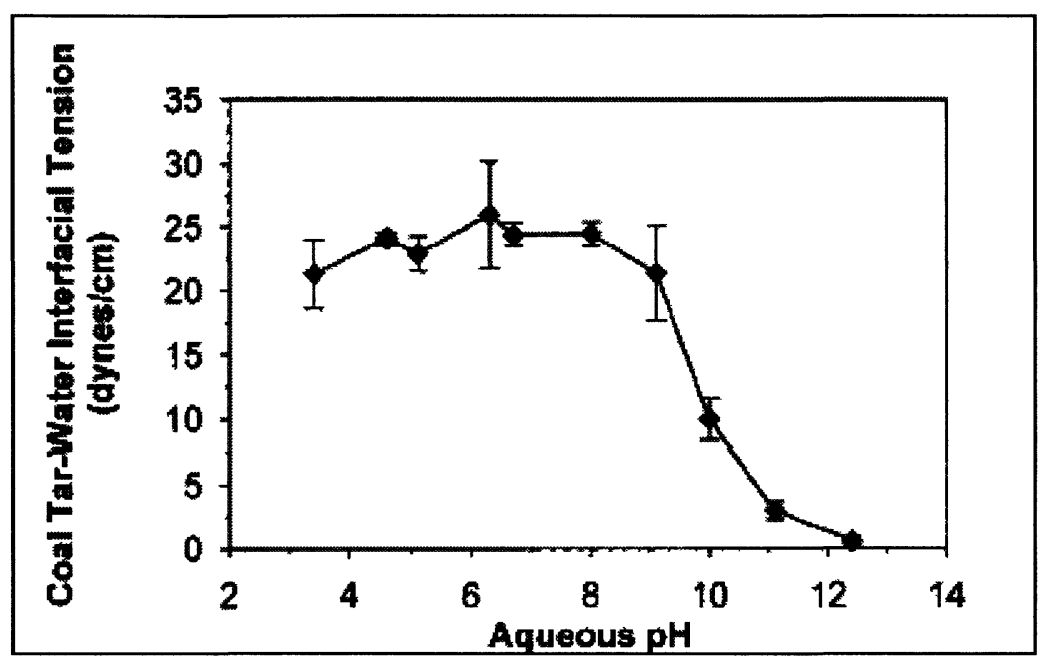

Figure 2.5: Measured Interfacial Tension Values with Varying pH Values. (Taken From Baranko and Dawson, 1999) 


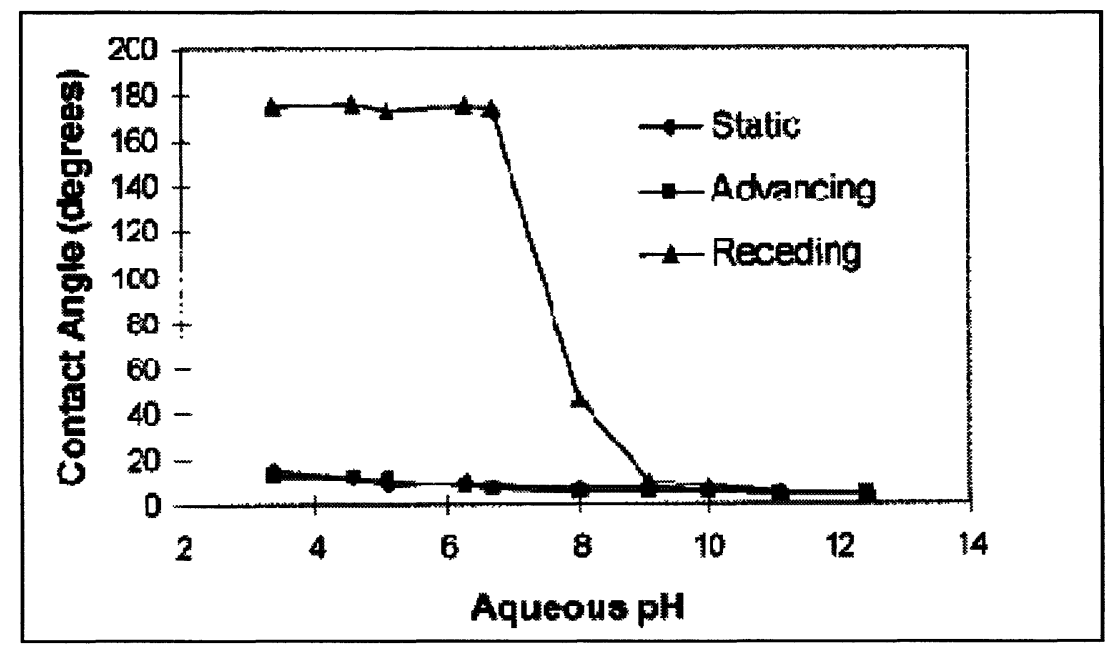

Figure 2.6: Measured Static, Advancing, and Receding Contact Angle Values with Varying pH Values. (Taken From Baranko and Dawson, 1999)

Another study by Molnar (2009) showed the effect of $\mathrm{pH}$ and surface charge on PCE-water interfacial tension on quartz sand and iron oxide plates. Dodecylamine (DDA) was used throughout the study as the organic base additive, which is a cationic surfactant below pH of 10.6 (Molnar, 2009). Results show that at pH of 6.5 and DDA concentration of $0.0027 \mathrm{M}$, quartz sand exhibited hydrophobic conditions while the iron oxide plates remained in their hydrophilic form. Figure 2.4 presents the receding contact angle formed along the PCE-water interface at $\mathrm{pH}$ of 6.5 and DDA of $0.0027 \mathrm{M}$. 


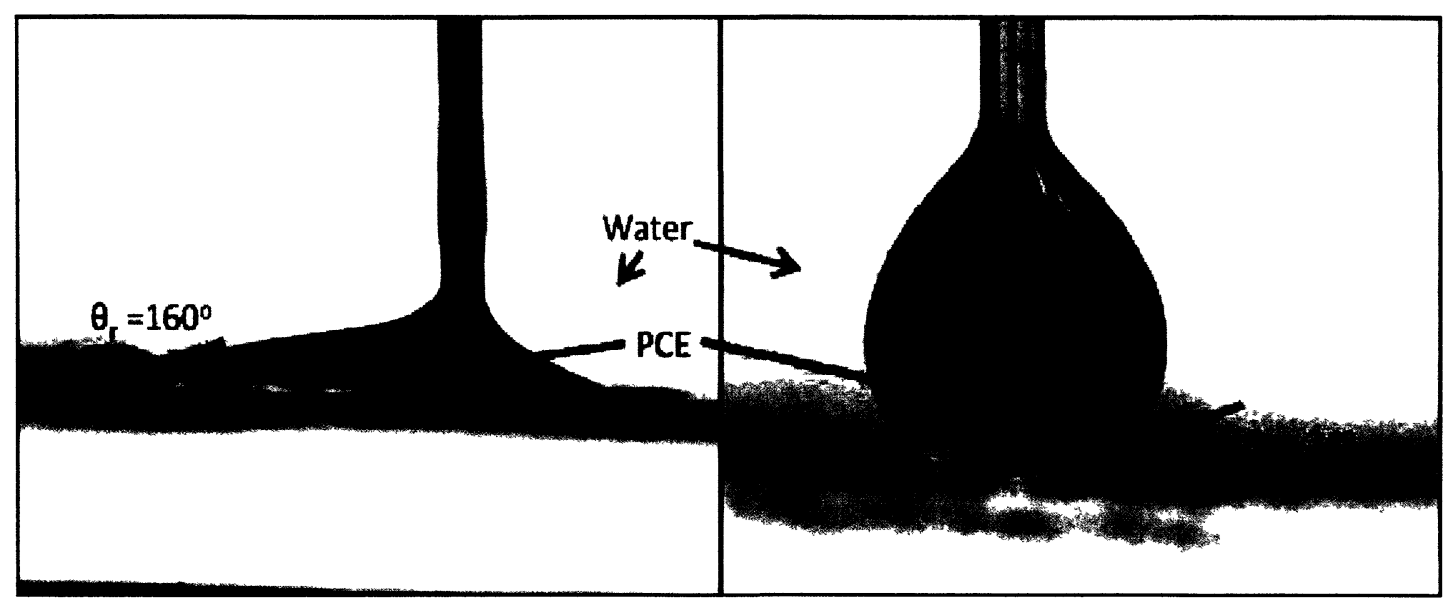

Figure 2.7: Receding PCE droplets on Quartz (Left) and Iron Oxide Plates (Right) Initially Immersed in Water at pH of 6.5 at DDA of 0.0027M. (Taken From Molnar, 2009)

Zheng and Powers (1999) also showed the effect of aqueous phase $\mathrm{pH}$ on the wettability of the porous media through bottle tests and visually assessing the wettability preferences that resulted. Coal tar and water were used as the fluid phases in this study. Quartz sand was used as the soil medium as it represents most of the soil minerals. Quartz sand was initially wet by water with an initial saturation of $10 \%$. Bottle tests were undertaken at two different $\mathrm{pH}$ values: 4.7 and 6.3. At $\mathrm{pH}$ value of 4.7, coal tar wet the soil grains and resulted in NAPL-wet soil medium, whereas, at $\mathrm{pH}$ value of 6.3 , water tends to wet the soil grains and resulted in water-wet soil medium.

Based on the previous studies, it can be concluded that the aqueous phase $\mathrm{pH}$ as well as the surface charge had a significant effect on: interfacial tension, contact angle values and the wettability of porous media as a whole. It was also concluded that the presence of polar constituents (asphaletenes) are the main reason why different values and relationships can be obtained upon the variation of the aqueous phase $\mathrm{pH}$. These 
variations in values and relationships, due to the variation of the aqueous phase $\mathrm{pH}$, will in turn affect the applied remediation technologies and impact their efficiencies.

\section{Oil Production Related Research}

Different degrees of wettability have shown to induce many inconsistencies within oil production fields. In water-wet reservoirs, oil resides in the larger pores due to capillary forces as a non-wetting fluid, whereas, water resides in the smaller pores and preferentially exists as a film around the reservoir formation. Laboratory and field studies have shown that oil production from water-wet formations is relatively easier than that in oil-wet reservoirs because higher recovery efficiencies and performance can be achieved within water-wet oil reservoirs. Spontaneous imbibition rate of the wetting fluid within the core samples is considered as the most reliable way of determining the formation's wettability (Denekas et al., 1958). However, several concerns were raised considering alteration of the wetting preferences of the whole reservoir formation or on the small scale of core samples collected. Several studies have shown that the use of drilling fluids during coring of the samples may cause wettability alteration of the formation resulting in lower recovery efficiency. Others have shown that the inappropriate handling and testing also can promote wettability alteration processes to occur (Denekas et al., 1958).

This section will represent some of the oil producing issues that affect the core wettability during the coring process of the reservoir, handling, storage, and testing of the core.

Several studies have shown the effects of drilling mud during coring on the wettability of reservoirs and how they can totally alter the reservoir's wetting characteristics. The use of oil- or synthetic-based mud during drilling, which was proven 
to be very efficient, can render the reservoir's wettability through damaging the reservoir formation. These drilling fluids contain cationic or anionic surfactants which will have an effect on the overall zeta potential at the rock fluid interface (Donaldson, 2008). As a result, caution has to be undertaken towards the choice of the coring fluids and of the factors that may alter reservoir's wettability.

Donaldson (2008) reviewed one of the new invented drilling muds that was proven to be satisfactory and ensure high efficiency during drilling and production. The new invented "reverse invert emulsion" has the capability of maintaining oil-wet conditions during drilling and then its properties can be reversed to water-wet conditions after drilling. This maintains the formation water-wet during production, ensures higher petroleum recovery rates, and prevents formation damage.

Cores samples are exposed to different environmental conditions after being removed from their native state (i.e. reservoir) and brought to the surface. Changes in the surrounding environment such as: temperature difference, pressure difference, and the new oxidizing environment are among the factors that were observed to change the samples' wetting preferences. Proper handling and storage can preserve the cores' wettability for several months. Some handling and storage methods were proposed in the literature. These methods' main goal is to inhibit the oxidation and the subsequent lose of light end hydrocarbons in oil (i.e. volatile compounds) that are found along with the core. One of the methods was to immerse the core material in "suitable synthetic brine" within glass tubes. The other proposed method is to wrap the core in "polyethylene film" and "aluminium foil". Both methods have to be undertaken immediately after the drilling process in order to minimize or inhibit oxidation. Imbibition rate tests were undertaken to 
compare results of those proposed packing procedures (preserved) and "well-site tests" (fresh cores). Satisfactory results were observed which indicated no significant changes occurred upon following procedures which inhibit the oxidation process (Denekas et al., 1958).

\section{Importance of Fines and Change in Wettability}

Some studies have revealed the wettability alteration effects associated with the presence of fine particles. Due to the net negative charge associated with clay minerals they may have the potential to attract positively charged polar compounds. Also due to their high specific areas, compared to sand, they may adsorb more positively charged polar compounds.

A study by Liu et al. (2003) confirmed the presence of residual hydrocarbons within quartz sand. These trapped hydrocarbons were mainly attached to the fine clay fractions existing within the quartz grains. The presence of fine clay particles was confirmed using the scanning electron microscope (SEM) and an energy dispersive X-ray (EDAX) system. It was concluded in the study that the presence of fine clay particles on quartz grain surface may have enhanced a change in wettability of the originally waterwet quartz sand.

Changes due to the presence of fines fraction was pointed out by many studies referenced in Anderson's (1987) wettability survey, part four, titled "effects of wettability on capillary pressure". The presence of fines fraction influenced the irreducible water saturation in the $P_{c}-S$ relationship. Similar behaviour was reported by many studies when comparing native state cores versus same cores after cleaning and rendered water-wet. Fatt and Klikoff (1959) demonstrated the significant effects of the fines fraction if they 
were rendered NAPL-wet. Fatt and Klikoff's (1959) work will be discussed in greater details in the discussion of the results of this study.

Based on the research conducted to date and the recent findings for intermediateto NAPL-wet soils, either by nature or due to one or more potential factors mentioned in literature, our conceptual understanding of the migration, distribution, and remediation of NAPL in the subsurface will be greatly affected. The presence of intermediate- to NAPLwet soils and also the possible wettability alteration due to the potential factors mentioned can change the subsurface wetting preferences at a certain location. This existence of these types of soils at a certain location exhibit different behaviours than the ideal behaviour environmental practitioners are used to. Different approaches to assess the wettability of subsurface soil after being subjected to one or more of those identified factors that impact wettability were undertaken in this research. 


\section{Chapter 3. MATERIALS AND LABORATORY EXPERIMENTS}

As the main objective of the research was to ensure relevance to real world conditions, field soils were used in this research. Soil samples were collected from a former truck stop near HWY 401 west of the Ontario-Quebec border, where leakage had occurred from underground storage tanks used to store diesel. Two soil samples were collected from the fill soil that was placed around the tanks during installation: soil collected beside one of the storage tanks where no evidence of direct contact with diesel was reported called, "clean soil" in this thesis, and diesel-impacted soil collected just below one of the leaking tanks called "contaminated soil" in this thesis.

\subsection{Soil and Fluid System Properties}

The porous medium used in the experiments was classified as a coarse to medium sand according to the ASTM classification. Two samples of the porous media were obtained from the truck stop, as mentioned earlier, where the clean soil sample served as a benchmark for comparing with the contaminated sample. The collected soil samples were the fill material placed around the tanks when they were installed. Figure 3.1 shows the location where the soil samples were collected from.

Fluids used in this study were diesel and water pre-equilibrated with diesel. Diesel was purchased at a local station because no free product was collected at the site. The diesel was dyed red using Sudan III so as to visually distinguish between water and diesel in laboratory experiments. Water was allowed to pre-equilibrate with diesel by adding approximately five times the mass needed to reach the solubility limit of diesel in water, which is 0.5 grams/litre, and shaking for three to four days. 


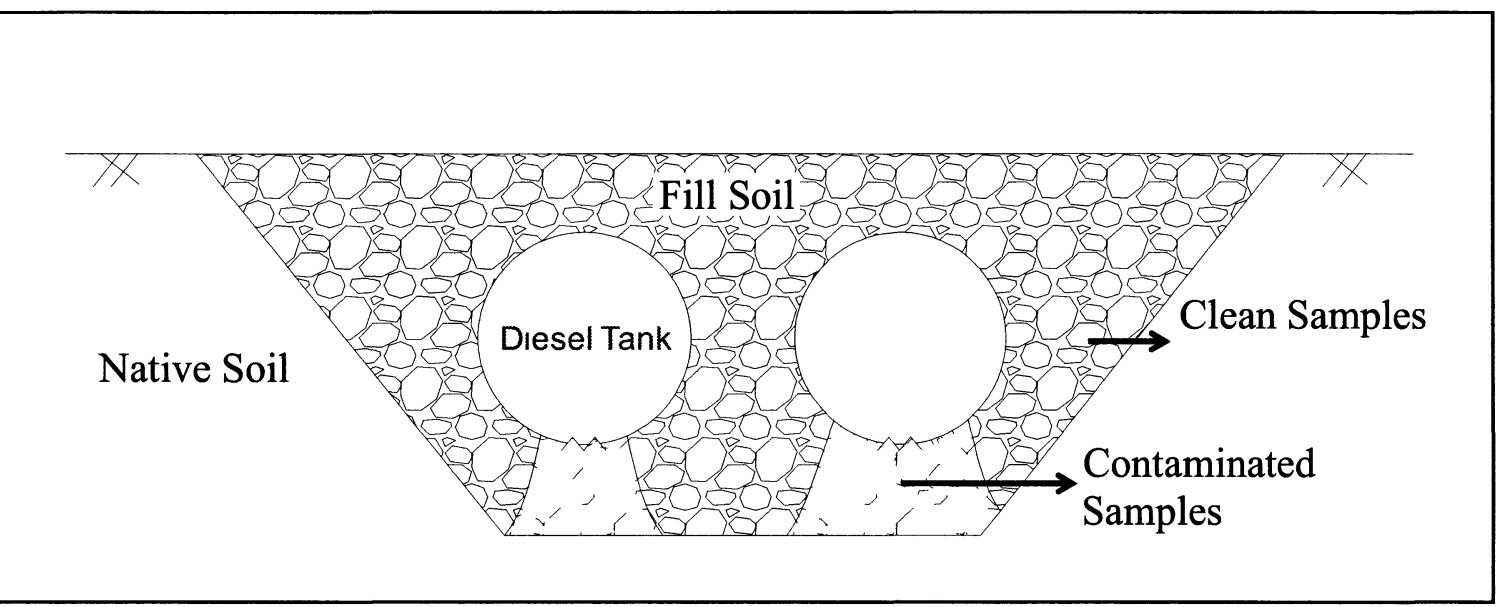

Figure 3.1: Schematic Diagram of the Collected Soil Samples Location and the

\section{Diesel Tanks.}

\subsubsection{Soil medium properties}

Physical and chemical properties of the soil were examined. For the purpose of the study, the contaminated soil samples were divided into two types: wet contaminated soil (i.e. as received) and air-dried contaminated soil (i.e. in absence of water). The contaminated soil was allowed to air dry by spreading the soil on an aluminium foil and aerating for a period of time followed by a moisture content calculation. The purpose of dividing the contaminated soil into wet and air-dried contaminated soil was that air-dried soil samples were needed to conduct capillary pressure-saturation $\left(P_{c}-S\right)$ experiments such that the samples could be flushed with $\mathrm{CO}_{2}$ to generate $100 \%$ saturation conditions to start the $P_{c}-S$ experiments. The air drying process may have impacted the distribution of diesel compounds within the soil and this is discussed later in the thesis. 


\section{Particle size distribution}

Soil samples were air-dried and then particle size distribution was undertaken. For the purpose of this study, soil particles retained on sieve number $10(>2 \mathrm{~mm})$ were discarded, and soils passing through sieve number 10 were used.

\section{Dry Density and Porosity}

Dry density $\left(\rho_{d}\right)$ is the mass of solids occupied within a certain known volume. A set of 10 known volumes of soil sample were weighed and an average dry density value was recorded. Porosity $(n)$ of soil medium describes the void fraction of the soil. Porosity values were calculated from the dry density using Equation 4.1

$$
n=1-\frac{\rho d}{G s}
$$

where $n$ is the porosity of the porous medium; $\rho d$ is the dry density; Gs is the specific gravity of pure quartz sand.

\section{Saturated Hydraulic Conductivity $\left(K_{\text {sat }}\right)$}

Saturated hydraulic conductivity was determined using the constant head test according to the ASTM standards on six soil samples and an average value was recorded.

\section{Total Petroleum Hydrocarbons (TPH)}

Soil samples were sent to Paracel Laboratories LTD. to assess the degree of contamination through measuring the TPH concentration of soil. One sample of both contaminated soil types; air-dried and wet contaminated soil samples were analyzed. 


\section{Organic Carbon Content $\left(f_{o c}\right)$}

Five samples were used to measure the organic carbon content for the soil according to the ASTM standards. Organic matter, usually expressed as organic carbon content, is considered the primary parameter to determine the sorption coefficient $\left(K_{d}\right)$ of the soil. Mass of sorbed contaminant $(S)$ into the soil is a function of the sorption coefficient $\left(K_{d}\right)$ which is in turn a function of the organic carbon content $\left(f_{\text {oc }}\right)$ of the soil and the octanol-water partitioning coefficient $\left(K_{o w}\right)$ (Karickhoff, 1981).

\subsubsection{Fluid Properties}

Some of the basic diesel properties were examined such as: interfacial tension (water equilibrated with diesel/air, diesel/air, and diesel/water equilibrated with diesel $($ dynes $/ \mathrm{cm})$ ). Interfacial tension measurements were done using a DuNouy ring tensiometer, with a precision of \pm 0.1 dynes $/ \mathrm{cm}$. Prior to use, the ring was immersed in acetone and then wiped away to ensure the removal of any residual organic compounds. Twenty interfacial tension measurements were taken and an average value was recorded. Other properties such as: viscosity $(\mathrm{cp})$ and density $\left(\mathrm{g} / \mathrm{cm}^{3}\right)$ were obtained from the literature.

\subsection{Laboratory Experiments}

Three different experiments were conducted to assess soil wettability.

\subsubsection{Visual Observation Experiments}

Static drops added to a soil can give a strong indication of the wettability of the soil depending on whether the fluid introduced will be drawn into the soil or a droplet of will be formed at the surface. In this work, no dimensions were calculated for the drop, 
only visual observation of the behaviour of the introduced water phase was considered. The formation of a water droplet on the surface or if it is drawn into the soil depends mainly on the wettability at the outer surface of the soil grain.

\subsubsection{Imbibition Rate Tests}

Water and diesel imbibition rate tests were carried out using Buchner funnels. Buchner funnels have a volume of $350 \mathrm{~mL}$ and are equipped with a water-wet ceramic porous plate with an air entry pressure of 0.5 bars.

To set up a water imbibition rate test, the porous plate was flushed with $\mathrm{CO}_{2}$ for ten minutes to displace the air phase existing within the ceramic porous plate. It is easier for $\mathrm{CO}_{2}$ to dissolve in water that for air to dissolve in water. The funnel was then connected to a water filled burette and ten pore volumes of water were used to flush the porous plate. Excess water was then drained from above the plate. The water level in the burette was aligned at the same elevation as the top part of the ceramic porous plate and then the flow valve in the water burette was closed to maintain that elevation. Then a dry soil sample of a known weight was packed into the funnel.

To begin the experiment, the initial water volume in the burette $\left(\mathrm{WV}_{\text {initial }}\right)$ was recorded. The burette flow valve was then opened and the rate of water that spontaneously imbibed into the dry soil sample was recorded with time. The volume of water withdrawn from the burette was measured at regular intervals over a 100-minute period. The final water volume in the burette $\left(\mathrm{WV}_{\text {final }}\right)$ and the final suction $\left(\mathrm{P}_{\mathrm{c}}\right)$ were recorded as shown in Figure 3.2. The same procedure was followed for diesel imbibition rate tests. 


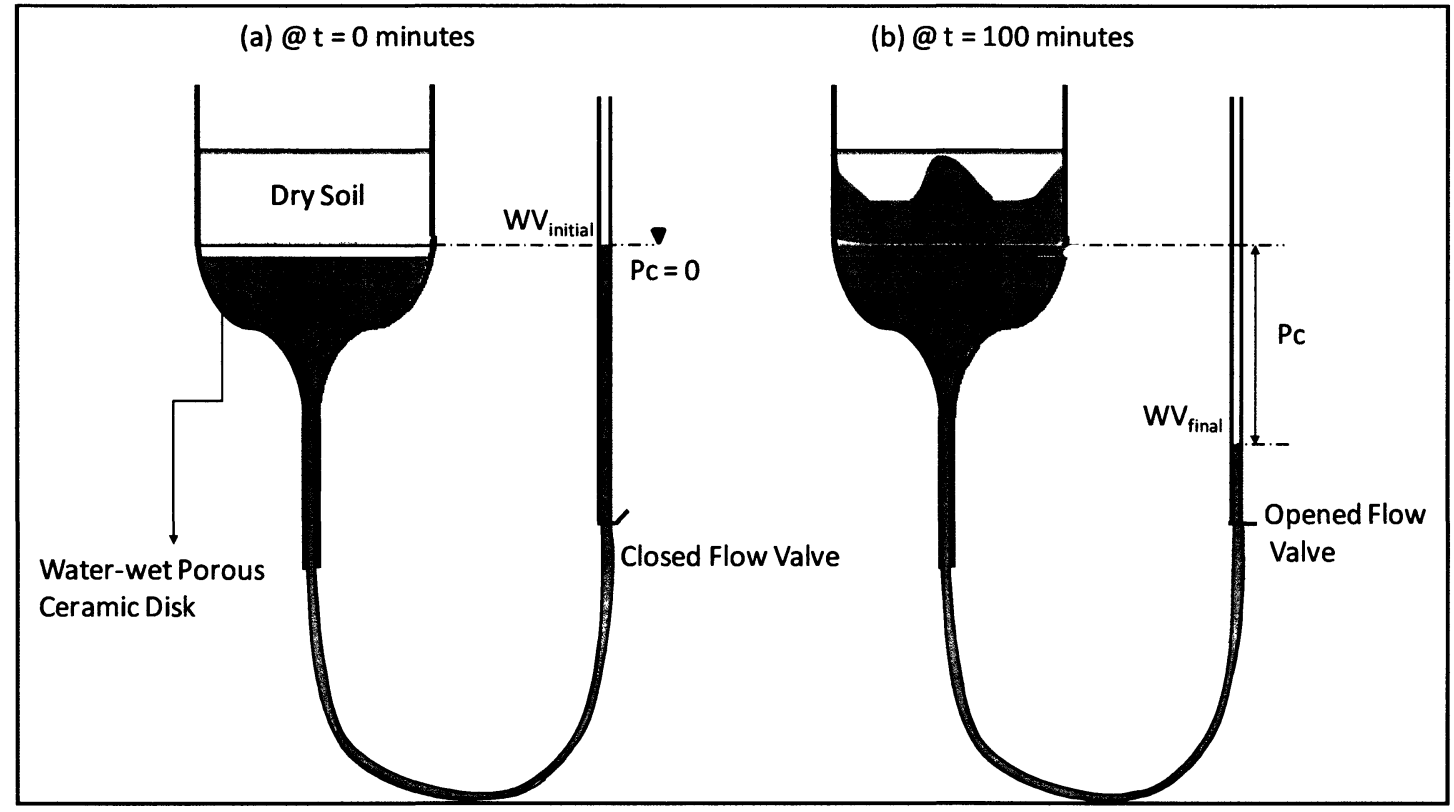

Figure 3.2: Water Imbibition Rate Test (a) At Time (t) = 0 Minutes; and (b) At (t)

$$
=100 \text { Minutes. }
$$

\subsubsection{Capillary Pressure-Saturation $\left(P_{c}-S\right)$ Experiments}

Capillary pressure-saturation $\left(P_{c}-S\right)$ experiments were conducted using pressure cells. The pressure cells were based upon the design of Salehzadeh and Demond (1999) but with a larger cell volume $\left(39.3 \mathrm{~cm}^{3}\right)$. Pressure cells were made of aluminium and composed of three main parts: upper, lower, and middle parts (cell chamber). The upper and lower parts of the cell were of the same dimensions. Both upper and lower parts were fastened to the cell chamber using six screws. Pressure cell components and dimensions are presented in Figures 3.3 through 3.9. Two porous membranes were added between the cell chamber and both the upper and lower parts. The lower filter membrane was a waterwet $0.45 \mu \mathrm{m}$ polyvinylidene fluoride (HVLP, Millipore) while the upper filter membrane was a NAPL-wet $0.45 \mu \mathrm{m}$ polyvinylidene fluoride (HVHP, Millipore) membrane. These membranes had a reported hydraulic conductivity of $29 \mathrm{~mL} / \mathrm{min} / \mathrm{cm}^{2}$ and an air entry 
pressure of 1.55 bars. Both membranes rested in a $0.16-\mathrm{cm}$-thick porous stainless steel support (20 $\mu \mathrm{m}$, Mott Metallurgical, Farmington, Conn.). The stainless steel support in turn rested in a $0.16-\mathrm{cm}$-thick recession (Figure 3.4) and sealed by two Viton o-rings (Schooner Bearing Services, Ottawa).

Two phase (diesel/water) capillary pressure-saturation experiments were generated for both air-dried and initially wet soil samples using pressure cells. As mentioned earlier, the contaminated soil was divided into two types, wet and air-dried contaminated soils. Both soil types were addressed using the pressure cells but with different procedures, as illustrated later. Air-dried soil samples allow the soil sample to be flushed with $\mathrm{CO}_{2}$, which in turn will help achieve an initial saturation of $100 \%$. Initially wet soil samples do not allow the sample to be flushed with $\mathrm{CO}_{2}$ as the porous plate will get wet and restrict the $\mathrm{CO}_{2}$ flow into the sample. Hence, $100 \%$ initial saturation could not be achieved. The two procedures are in detail later in this section. 


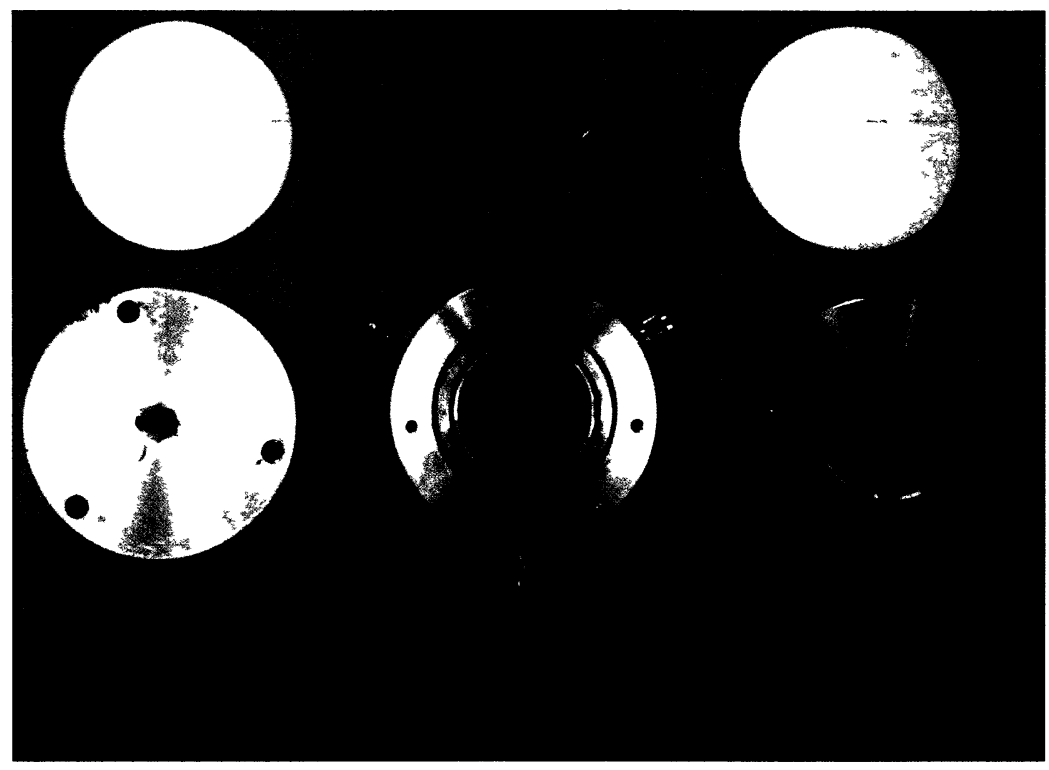

Figure 3.3: Pressure Cell Components.

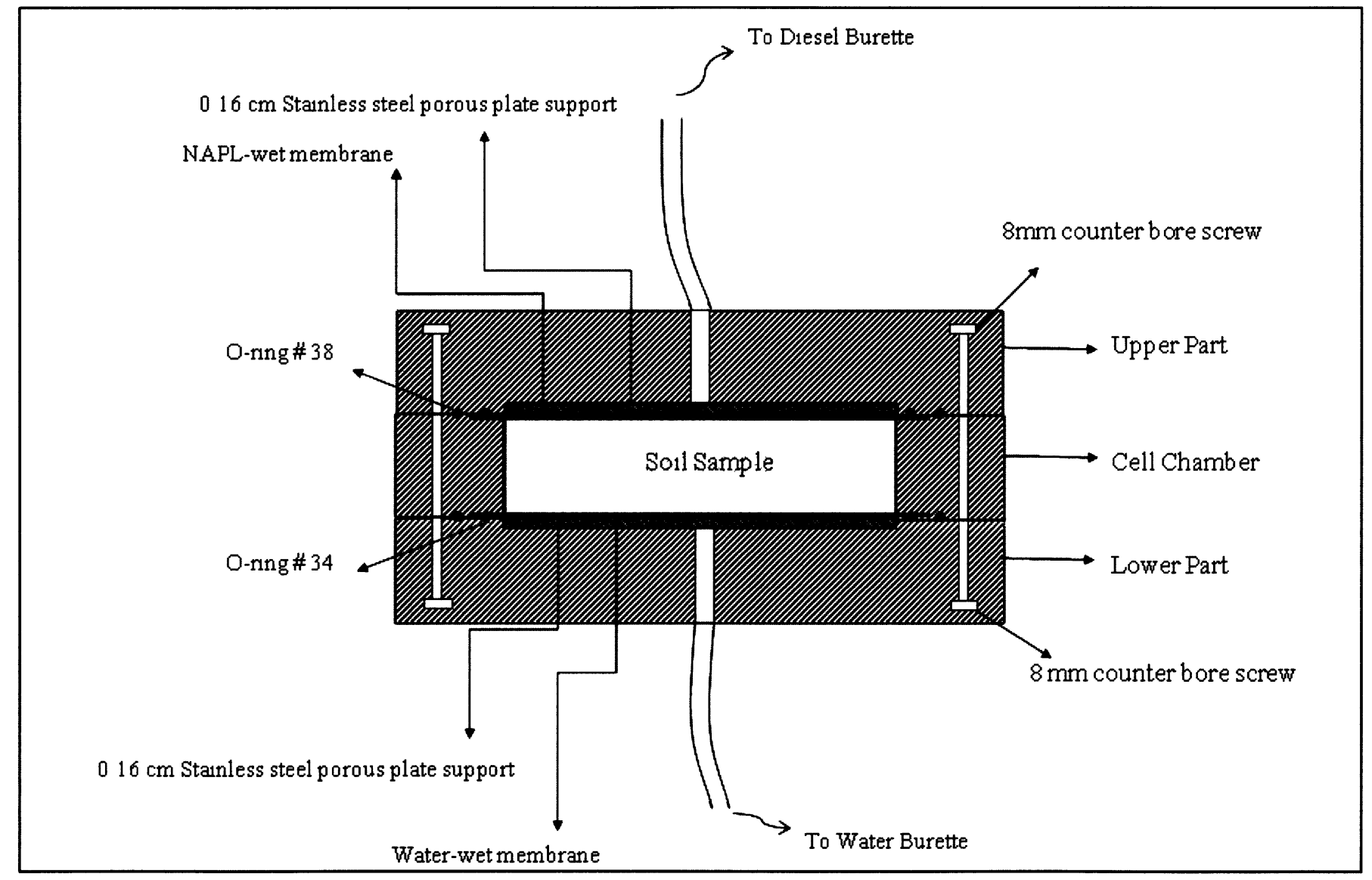

Figure 3.4: Schematic Diagram of Pressure Cell. 


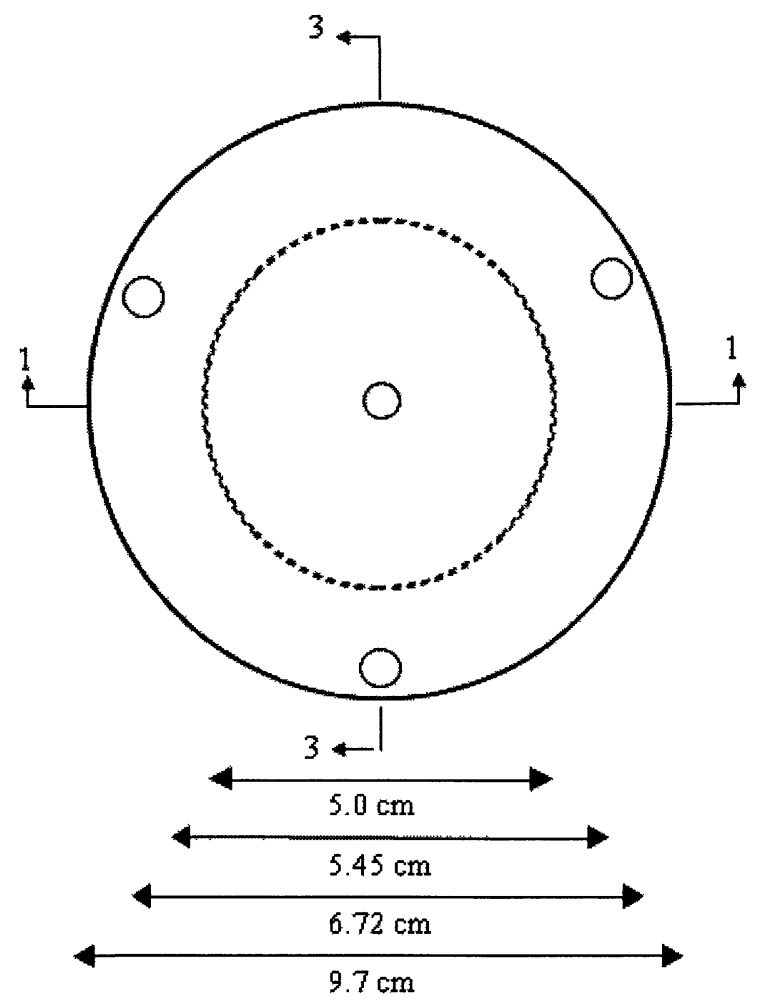

Figure 3.5: Top and Bottom Parts of Pressure Cell (Plan View).

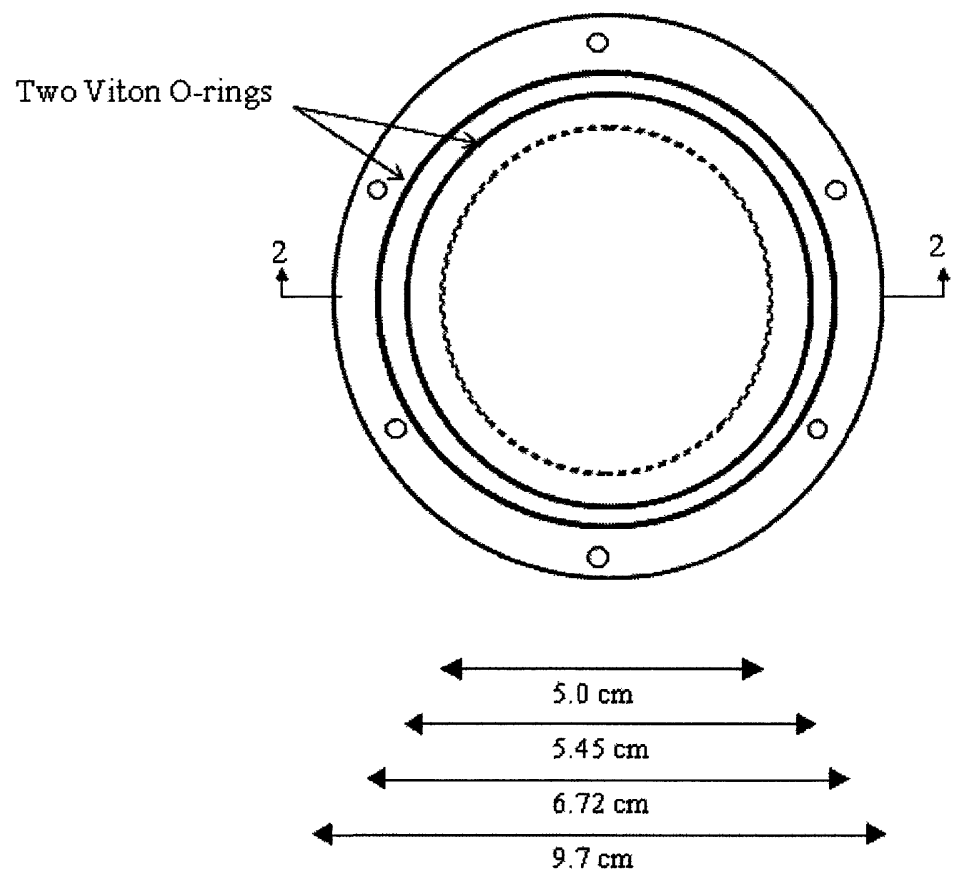

Figure 3.6: Middle Part of Pressure Cell (Plan View). 

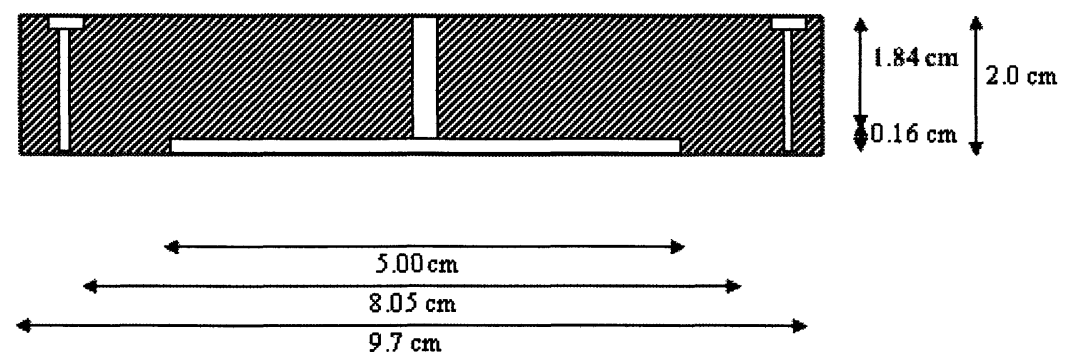

Figure 3.7: Section 1-1.
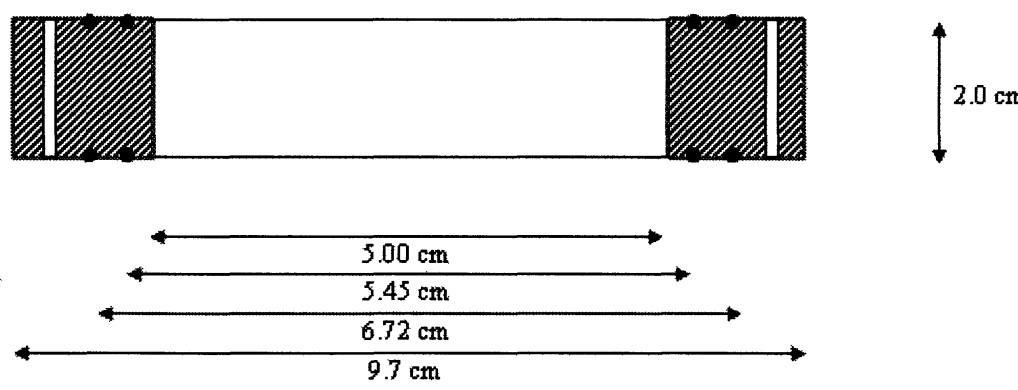

Figure 3.8: Section 2-2.
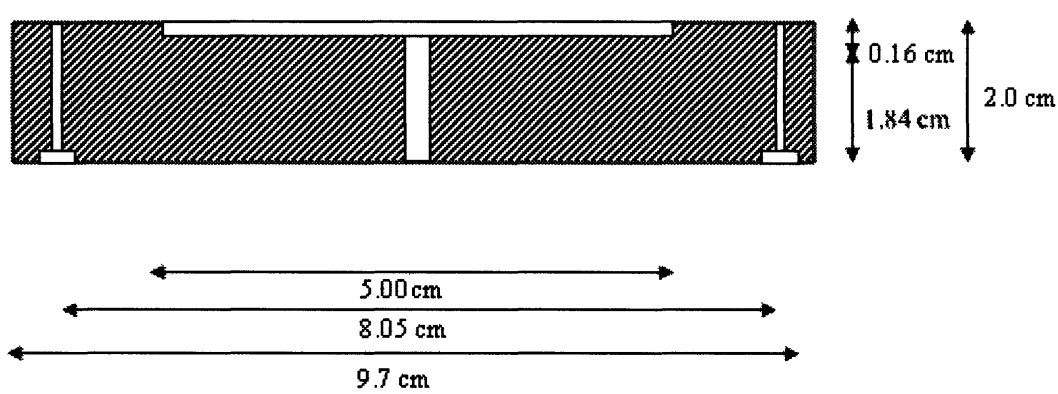

Figure 3.9: Section 3-3.

\subsection{3.a. Air-Dried Soil Sample Experimental Procedure}

The $P_{c}-S$ experiments for the air-dried soils were conducted first. Since the objective of this research was to determine if wettability changes may have occurred due to the prolonged exposure to diesel and given that the fines fraction of the soil will raise the $P_{c}-S$ curve and increase the time needed to reach equilibrium, fines fraction passing 
sieve number 100 was removed in order to reduce the time needed to complete a $P_{c}-S$ experiment. The fines fraction was also removed for the visual observation test and imbibition rate tests, which both start with dry soil samples. Figure 3.10 presents the soil used as the air-dried soil samples.

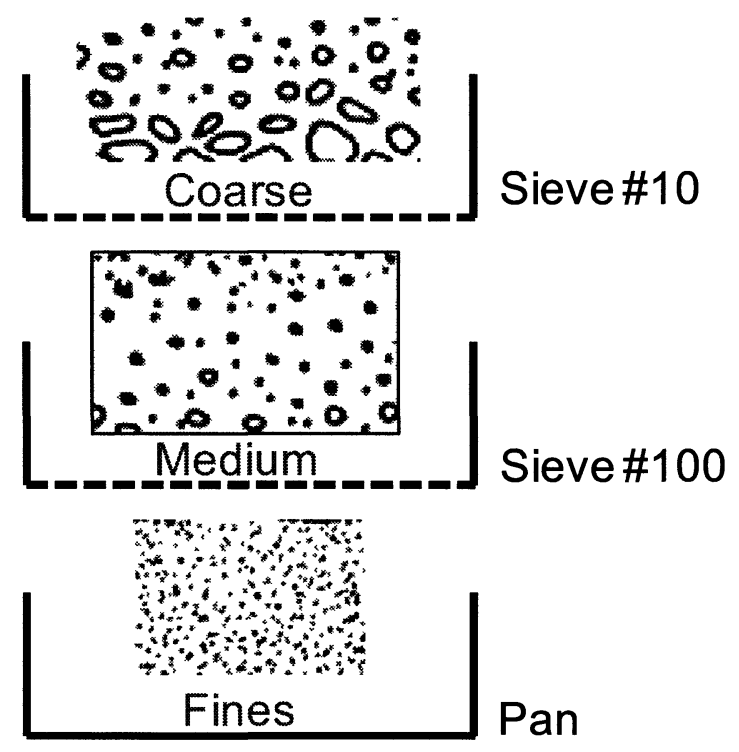

Figure 3.10: Air-Dried Soil Samples Used (Without Fines).

To set up the experiment, a stainless steel porous plate support, a water-wet filter membrane, and two o-rings were placed on the lower part of the cell. The water-wet filter membrane was placed such that it covered the inner o-ring; see Figure 3.4 for more details. The cell chamber was then fastened to the lower part using three screws. The dry soil medium was added into the cell chamber in $0.5 \mathrm{~cm}$ lifts. After each lift was added, the entire cell was vibrated and packed using a stainless steel tamper. The same packing technique was followed for each lift until the cell was full of the soil medium. The stainless steel porous plate support, water-wet filter membrane, and the two o-rings in upper part of the cell were fastened to the cell chamber using three screws. The cell was then flushed with $\mathrm{CO}_{2}$ for ten minutes in order to displace the air within the soil pore 
volume, and then flushed with hundred pore volumes of water to ensure a hundred percent saturation within the porous medium. After flushing the soil medium with water, the upper part of the cell along with components had to be replaced. The water-wet filter membrane and the stainless steel porous support were replaced with a diesel saturated NAPL-wet filter membrane and stainless steel porous support. The upper part of the cell, which was already connected to a diesel-filled burette, was then carefully placed on the top of the cell chamber and fastened using three screws. The diesel level in the diesel burette was maintained just below the centre line of the cell to ensure that water was not displaced from the soil matrix. The water reservoir was maintained just above the centre line of the cell to maintain a slight negative capillary pressure and $100 \%$ water saturation. The experiment at that time was ready to proceed. This procedure is similar to that used by Chen et al. (2009).

To begin the experiment, the water burette should be lowered in order to achieve a zero capillary pressure head. To start the drainage curve, the water burette was lowered in steps, whereas, the diesel burette was raised in steps. After each step, adequate time was given in order for the system to reach equilibrium so as to achieve static capillary pressure-saturation relationship. O'Carroll et al. (2005) assumed equilibrium to be achieved when the difference in saturation was less than 0.8 percent of the total water displaced/entered the system at each increment. The difference in pressure heads between diesel and water represents the capillary pressure. Upon increasing the capillary pressure along the drainage pathway, a certain amount of NAPL (i.e. diesel) replaced the water existing in the soil sample and a corresponding amount of water was collected in the water burette. The drainage pathway was continued until only a small volume of water $(\leq$ 
$0.1 \mathrm{ml}$ ) was collected in the burette due to lowering the water burette or raising the diesel burette. Irreducible water saturation inside the soil sample was achieved at that point.

To start the wetting curve, the whole process was reversed. The water burette was raised in steps and the diesel burette was lowered and an adequate time was given as to reach equilibrium. Upon decreasing the capillary pressure along the wetting pathway, a certain amount of diesel exited the soil and re-entered the diesel burette and a corresponding amount of water entered the soil from the water burette resulting in an increase in the degree of saturation of water inside the sample. Wetting pathway was continued until the capillary pressure reached zero. Three tests were conducted for airdried clean soil and air-dried contaminated soil.

\subsection{3.b. Initially Wet Soil Sample Experimental Procedure}

Based on the preliminary results of the $P_{c^{-}} S$ experiments for the air-dried soils, it was needed to evaluate the $P_{c^{-}} S$ relationships for the wet or as received soil samples. Hence, the two phase (diesel-water) $P_{c^{-}} S$ experiments conducted for the initially wet or as received clean and contaminated soils used all the soil passing sieve number 10 . This would include the fines fraction (passing sieve number 100) which was removed for the experiments conducted for the air-dried soils. Figure 3.11 presents the soil used as the initially wet soil samples. 


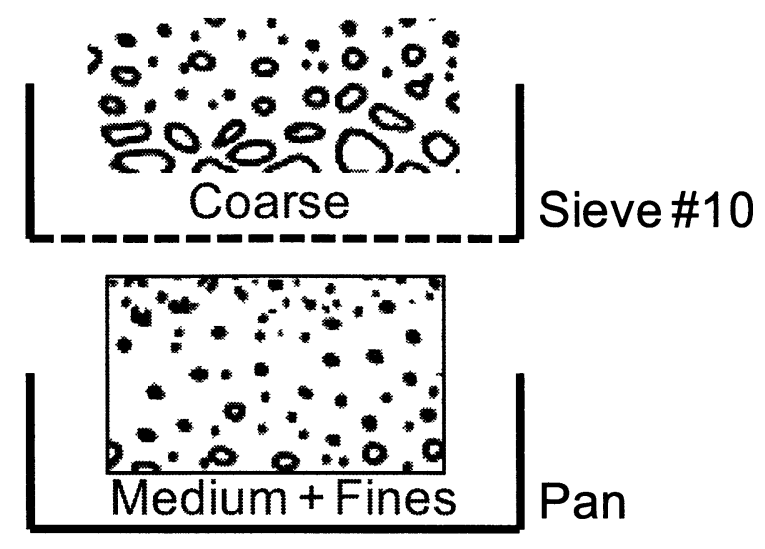

Figure 3.11: Initially Wet Soil Samples Used (With Fines).

To set up the experiment, a porous plate stainless steel support, water-wet filter membrane, and the o-ring were placed on the lower part of the cell. The cell chamber was then fastened to the lower part using three screws. The lower part and the cell chamber were flushed with $\mathrm{CO}_{2}$ for ten minutes and then flushed with ten pore volumes of water to ensure replacing the air phase within the stainless steel porous plate support and the water-wet membrane. Excess water in the cell chamber was then removed and a few millimetres $(\sim 5 \mathrm{~mm})$ of water was allowed to remain in the cell chamber with the aid of adjusting the water burette. The soil medium was added into the cell chamber in $0.5 \mathrm{~cm}$ lifts. After each lift was added, the entire cell was vibrated and packed using a stainless steel tamper and excess water was wiped away. The same packing technique was followed for each lift until the cell was full of the soil medium. The stainless steel porous plate support, water-wet filter membrane, and the two o-rings in upper part of the cell were fastened to the cell chamber using three screws. The cell was then flushed with ten pore volumes of water. After flushing the soil medium with water, the upper part of the cell along with components had to be replaced. The same procedures followed in the air- 
dried soil sample experimental procedure were followed through the end of the experiment.

Wet soil packing procedure results in a denser and more uniform soil medium according to Chen et al. (2009), however, the difficulty in starting the experiment at one hundred percent initial water saturation was observed. Recognizing the difficulty in achieving a fully water saturated conditions to commence the $P_{c}-S$ experiments, the initial water saturation was back calculated from the moisture content calculation at the end of each experiment. At the end of each experiment, the pressure cell was dismantled and the soil was weighed before and after a drying process. With the calculated moisture content and with the aid of mass balance of water that imbibed/drained through the system, the initial water saturation was back calculated. 


\section{Chapter 4. RESULTS}

This chapter presents the results obtained from comparing clean field soil versus both air-dried and wet contaminated soil. Laboratory test results include visual observation, water and diesel imbibition rate tests, and a series of two phase water-diesel capillary pressure-saturation $\left(P_{c^{-}} S\right)$ relationships.

\subsection{Soil Properties}

\section{Particle size distribution}

Table 4.1 and Figure 4.1 present particle size distribution for the collected soil samples (as received) after air drying and after removing the mass retained on sieve number 10.

Table 4.1: Particle Size Distribution.

\begin{tabular}{|c|c|c|}
\hline Sieve Number & Opening (mm) & Passing (\%) \\
\hline 10 & 2 & 100 \\
\hline 20 & 0.85 & 80.26 \\
\hline 40 & 0.425 & 28.79 \\
\hline 60 & 0.25 & 9.19 \\
\hline 70 & 0.212 & 7.52 \\
\hline 100 & 0.15 & 5.10 \\
\hline 200 & 0.075 & 3.01 \\
\hline Pan & - & 0.00 \\
\hline
\end{tabular}




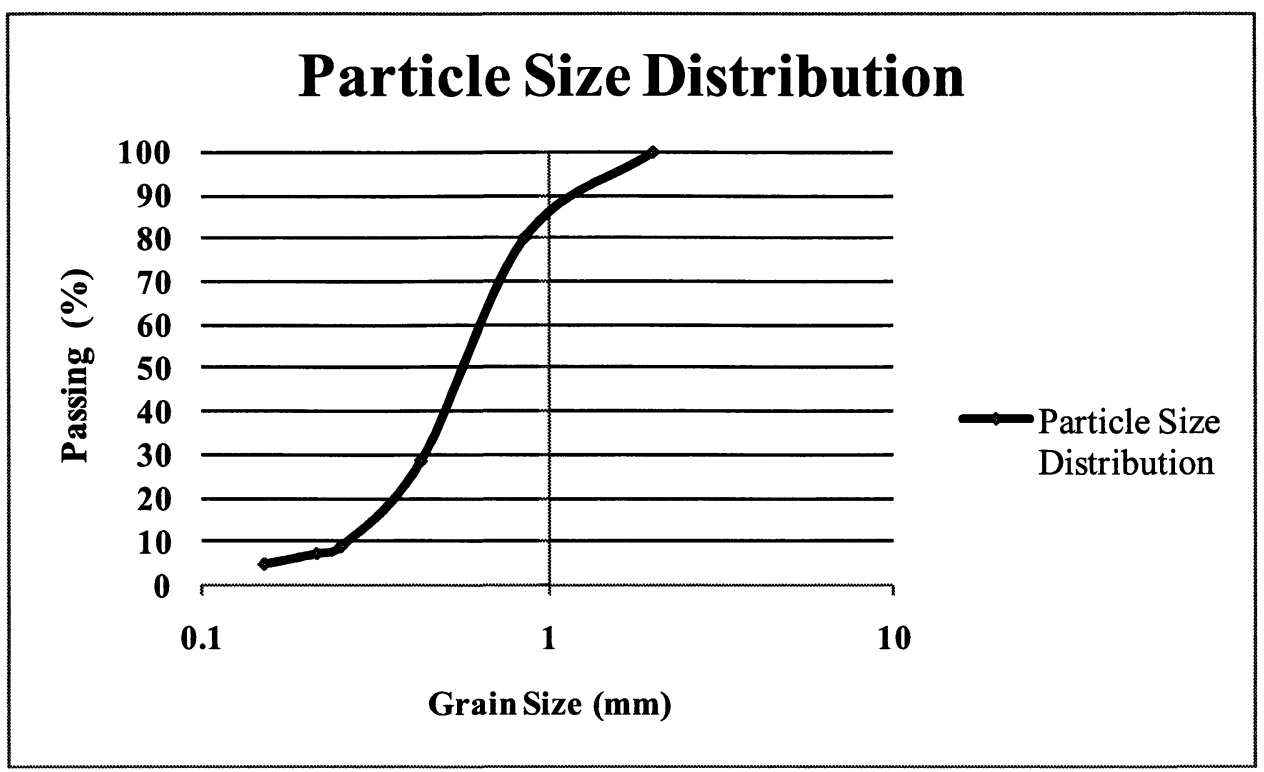

Figure 4.1: Particle Size Distribution.

Dry Density and Porosity

A set of ten known volumes of air-dried soil samples (i.e. without fines) were weighted and an average dry density and porosity were determined.

Table 4.2: Dry Density and Porosity Values.

\begin{tabular}{|c|c|c|}
\hline Trial & Dry Density $\left(\rho_{\mathbf{d}}\right)$ & Porosity (n) \\
\hline 1 & 1.7288 & 0.347 \\
\hline 2 & 1.6352 & 0.382 \\
\hline 3 & 1.5741 & 0.406 \\
\hline 4 & 1.5403 & 0.418 \\
\hline 5 & 1.5821 & 0.402 \\
\hline 6 & 1.6 & 0.396 \\
\hline 7 & 1.5945 & 0.398 \\
\hline 8 & 1.5727 & 0.406 \\
\hline 9 & 1.6671 & 0.37 \\
\hline 10 & 1.65 & 0.377 \\
\hline Average Values & 1.61448 & 0.3902 \\
\hline
\end{tabular}




\section{Saturated Hydraulic Conductivity (K)}

A set of six trials to determine the saturated hydraulic conductivity of air-dried clean soil were conducted and an average value was determined. A summary of these results is presented in Table 4.3.

Table 4.3: Saturated Conductivity (K) Values.

\begin{tabular}{|c|c|}
\hline Trial & K $(\mathrm{cm} / \mathrm{sec})$ \\
\hline 1 & 0.0218 \\
\hline 2 & 0.02196 \\
\hline 3 & 0.02252 \\
\hline 4 & 0.02814 \\
\hline 5 & 0.02956 \\
\hline 6 & 0.02781 \\
\hline Average Value & $\mathbf{0 . 0 2 5 3}$ \\
\hline
\end{tabular}

Total Petroleum Hydrocarbons (TPH)

TPH of contaminated soil sample was quantified using Gas ChromatographyFlame Ionization Detector (GC-FID) method. Both contaminated soil types; wet and airdried diesel contaminated field soils were quantified. Table 4.4 presents the TPH values obtained for initially wet contaminated and air-dried contaminated soil samples in $\mu \mathrm{g} / \mathrm{g}$ dry soil.

Table 4.4: TPH of Contaminated Soils.

\begin{tabular}{|l|c|c|c|}
\cline { 2 - 4 } \multicolumn{1}{c|}{} & Soil Sample: & Initially Wet & Air-Dried \\
\hline Hydrocarbons & MDL/Units & \multicolumn{2}{|c|}{} \\
\cline { 3 - 4 } TPH (Diesel) & $10 \mu g / g$ dry & 3220 & 1850 \\
\hline
\end{tabular}

where MDL is the Minimum Detection Limit of the apparatus used. 
Results showed that the initially wet contaminated soil had TPH concentration of 3220 micro grams $(\mu \mathrm{g})$ per gram $(\mathrm{g})$ of dry solids, whereas, the air-dried contaminated soil had $1850 \mu \mathrm{g} / \mathrm{g}$. TPH values were further investigated to assess the magnitude and amount of "pure phase" diesel that might be within the wet contaminated samples and the distribution of diesel within the soil before and after the drying process.

An analysis was completed for the wet or as received contaminated soil to determine if pure phase diesel existed. The moisture content of the samples was estimated to determine the water content. The maximum soil concentration without the presence of pure phase diesel was then estimated assuming the water volume was at the solubility limit with diesel. The actual TPH concentration indicated $0.5-1 \%$ pure phase diesel existed within the wet contaminated soil. After air drying the wet contaminated soil samples, the TPH was $1850 \mu \mathrm{g} / \mathrm{g}$ within the air-dried soil samples which indicates that after drying a fraction (likely the lighter fraction) of the hydrocarbons volatilized. In addition, the water film that used to coat the soil grains would be removed. This allowed the diesel to be in direct contact with the soil grains after drying. It was hypothesized that the fraction of hydrocarbons and additives that remained after drying were in direct contact with the surface of the soil particles and may have sorbed onto the soil particle surface. Direct contact of the heavier hydrocarbons and additives may form a physical and/or chemical sorbed layer on the soil particle surface which may have the potential to change the wetting preferences of the soil. The degree or the magnitude of this formed layer depends mainly on the type of the soil mineral, NAPL composition, and the subsurface environment (Powers and Tamblin 1995).

\section{Organic Content $\left(f_{o c}\right)$}


Approximate organic carbon contents $\left(f_{o c}\right)$ were measured for the air-dried clean and air-dried contaminated soil samples. Average values were recorded as presented in Table 4.5. The difference in $f_{o c}$ values between the two soils indicates the presence of the sorbed contaminant (i.e. diesel) to soil grains. However, upon comparing $f_{o c}$ to the $\mathrm{TPH}$ of air-dried contaminated soil $(1850 \mu \mathrm{g} / \mathrm{g})$ it does not give consistent approximation of the diesel amount that may be sorbed to the soil particle surface.

Table 4.5: Organic Content of Air-Dried Clean and Air-Dried Contaminated Soil Samples.

\begin{tabular}{|c|c|c|}
\cline { 2 - 3 } \multicolumn{1}{c|}{} & Clean Soil Samples & Contaminated Soil Samples \\
\hline Trial & \multicolumn{2}{c|}{ Organic Content Fraction } \\
\hline 1 & $\mathbf{0 . 0 1 1}$ & $\mathbf{0 . 0 3 9 3}$ \\
\hline 2 & $\mathbf{0 . 0 1 2 4}$ & 0.037 \\
\hline 3 & $\mathbf{0 . 0 1 2}$ & 0.04 \\
\hline 4 & $\mathbf{0 . 0 1 2 5}$ & $\mathbf{0 . 0 3 9 7}$ \\
\hline 5 & $\mathbf{0 . 0 1 1 2}$ & $\mathbf{0 . 0 3 6 9}$ \\
\hline Average Values & $\mathbf{0 . 0 1 1 8 2}$ & $\mathbf{0 . 0 3 8 5 8}$ \\
\hline
\end{tabular}

\subsection{Fluid Properties}

Absolute (dynamic) viscosity (cp), interfacial tension (diesel equilibrated water/air, diesel/air, diesel/diesel equilibrated water (dynes/cm)), and density $\left(\mathrm{g} / \mathrm{cm}^{3}\right)$ are presented in Table 4.6. 
Table 4.6: Physical Characteristics of Fluids.

\begin{tabular}{|c|c|c|}
\hline Property & Fluid(s) & Value \\
\hline Absolute Viscosity & Water & $1^{\mathrm{a}}$ \\
(cp) & Diesel & $1.1-3.5^{\mathrm{b}}$ \\
\hline Surface Tension $^{\mathrm{c}}$ & Water/Air & 71.1 \\
(dynes/cm) $^{\mathrm{D}}$ & Diesel/Air & 28.7 \\
& Water/Deisel & 21.9 \\
\hline Density $^{\mathrm{d}}$ & Water & 1 \\
$\left(\mathrm{~g} / \mathrm{cm}^{3}\right)$ & Diesel & $0.8-0.85$ \\
\hline
\end{tabular}
a $\operatorname{ASTM}(1985)$ measured at $20^{\circ} \mathrm{C}$
b $\operatorname{ASTM}(1985)$ measured at $40^{\circ} \mathrm{C}$
c measured for this study at $25^{\circ} \mathrm{C}$
d NIPER (National Institute for Petroleum and Energy Research), Bartlesville, Oklahoma. measured at $20^{\circ} \mathrm{C}$

\subsection{Visual Observation Results}

A water droplet was introduced on both air-dried clean and air-dried contaminated soils. Water was shown to be drawn into the air-dried clean soil, whereas, it pooled and formed a water droplet on top of the air-dried contaminated soil. Figure 4.2 presents the observed behaviour of water on both soils. 


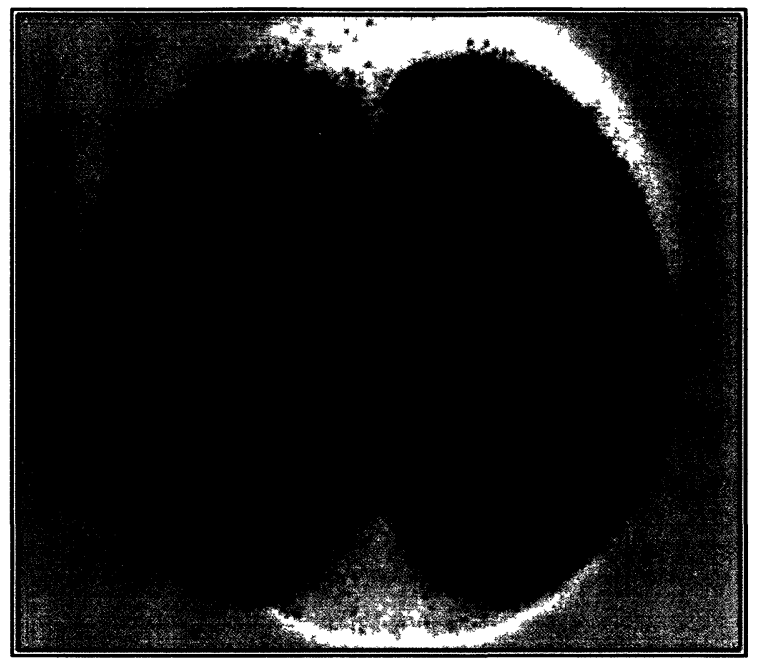

\section{Figure 4.2: Different Wetting Behaviours observed for Clean (Left) and Air-Dried Contaminated Soil (Right).}

The formation of the water droplet on the air-dried contaminated soil is an indication that the soil's wettability has been altered due to the prolonged exposure to diesel. The formation of the droplet may be attributed to the air drying process and sorption of the contaminant (diesel) along with the existing additives to the outer surface of the soil grain. As mentioned earlier, lab grade "pure" solvents are not expected to alter the soil's wettability but it is the additives that play an important role in the variation of the soil wetting preferences (Powers and Tamblin, 1995). These results were consistent with the results of Powers and Tamblin (1995) in terms of highlighting the role of additives and surface active agents on altering wetting characteristics of soil a medium after direct prolonged exposure.

Further investigation was done in order to assess the role of additives and whether short term exposure can alter the soil wetting characteristics by contacting air-dried clean soil to purchased diesel. A clean air-dried soil sample was contacted with diesel 
purchased at a local station in a quantity similar to that was determined from the TPH measurement for the wet contaminated or as received soil. The contact of diesel with the soil was for a 30-day period followed by air-drying the soil. Results showed that the airdried soil in contact with the purchased diesel preserved its water-wet preference and water was immediately drawn into the soil. Similar water-wet behaviour was observed for air-dried clean soil sample. These results indicate that the changes observed in wettability for the field soil occurred due to the prolonged exposure to diesel and that the 30 days was an insufficient period to cause changes or that the additives in the purchased diesel from a local station were different from those found in the field diesel. In addition, the environmental conditions in the lab may not have reflected the proper conditions that occurred at the field during the prolonged exposure.

\subsection{Imbibition Rate Results}

Figure 4.3 presents water imbibition rate for the air-dried clean and air-dried contaminated soil. The rate and amount of water imbibed into the air-dried clean soil was greater than for the air-dried contaminated soil. Higher actual water saturation was observed in the clean soil compared to the air-dried contaminated soil after 100 minutes. Actual water saturations of 45 and 13 percent were achieved for air-dried clean and airdried contaminated soil, respectively. Maximum capillary pressures reached of $10 \mathrm{~cm}$ and $3.4 \mathrm{~cm}$ were recorded for the air-dried clean and the air-dried contaminated soil. 


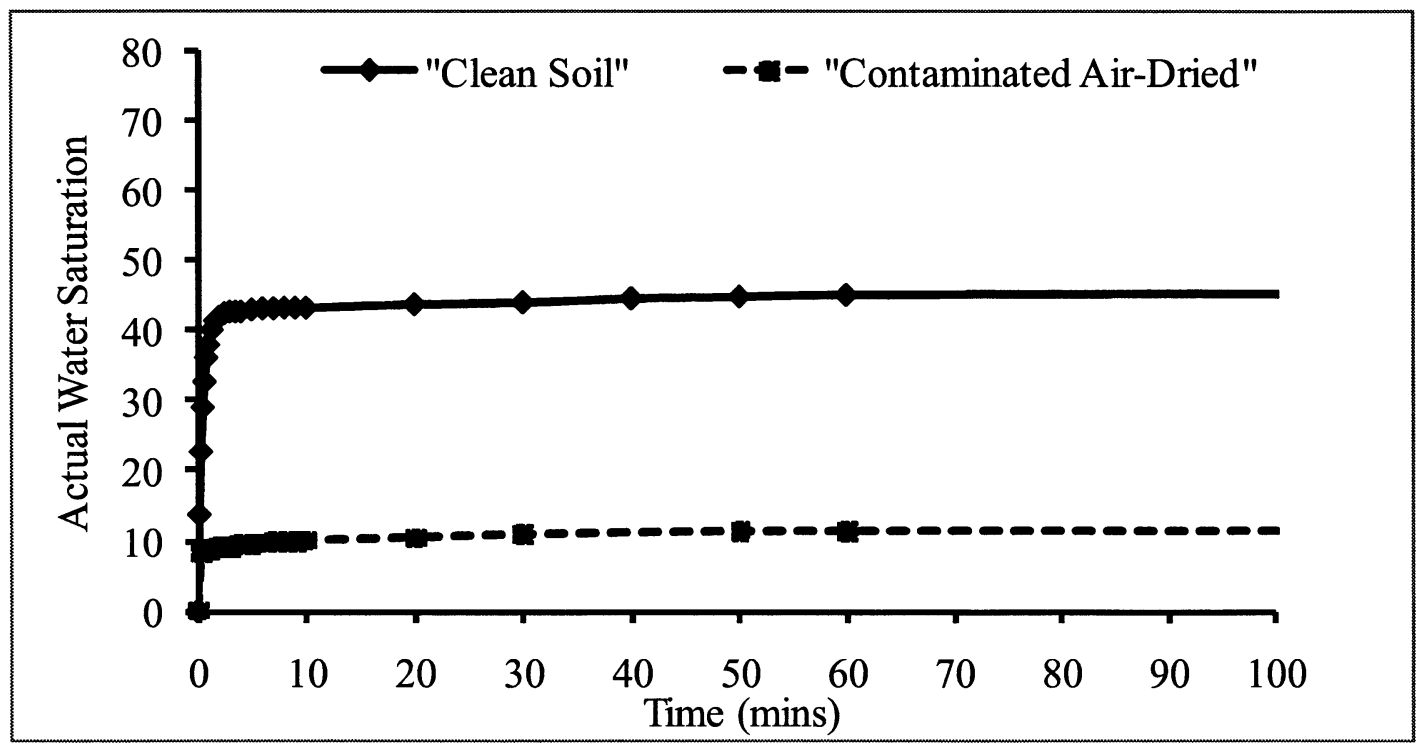

Figure 4.3: Water Imbibition Rate in Air-Dried Clean and Air-Dried Contaminated Soil Samples.

Figure 4.4 presents diesel imbibition rate for the air-dried clean and air-dried contaminated soil. Note that the soils' wetting preferences towards water and diesel had changed. Diesel imbibed into the air-dried contaminated at a greater rate and a larger amount compared to the air-dried clean soil. Actual diesel saturations of 35 and 41 percent were achieved for air-dried clean and air-dried contaminated soil, respectively. Maximum capillary pressures of $8.7 \mathrm{~cm}$ and $10 \mathrm{~cm}$ were recorded for the air-dried clean and the air-dried contaminated soil as, respectively. 


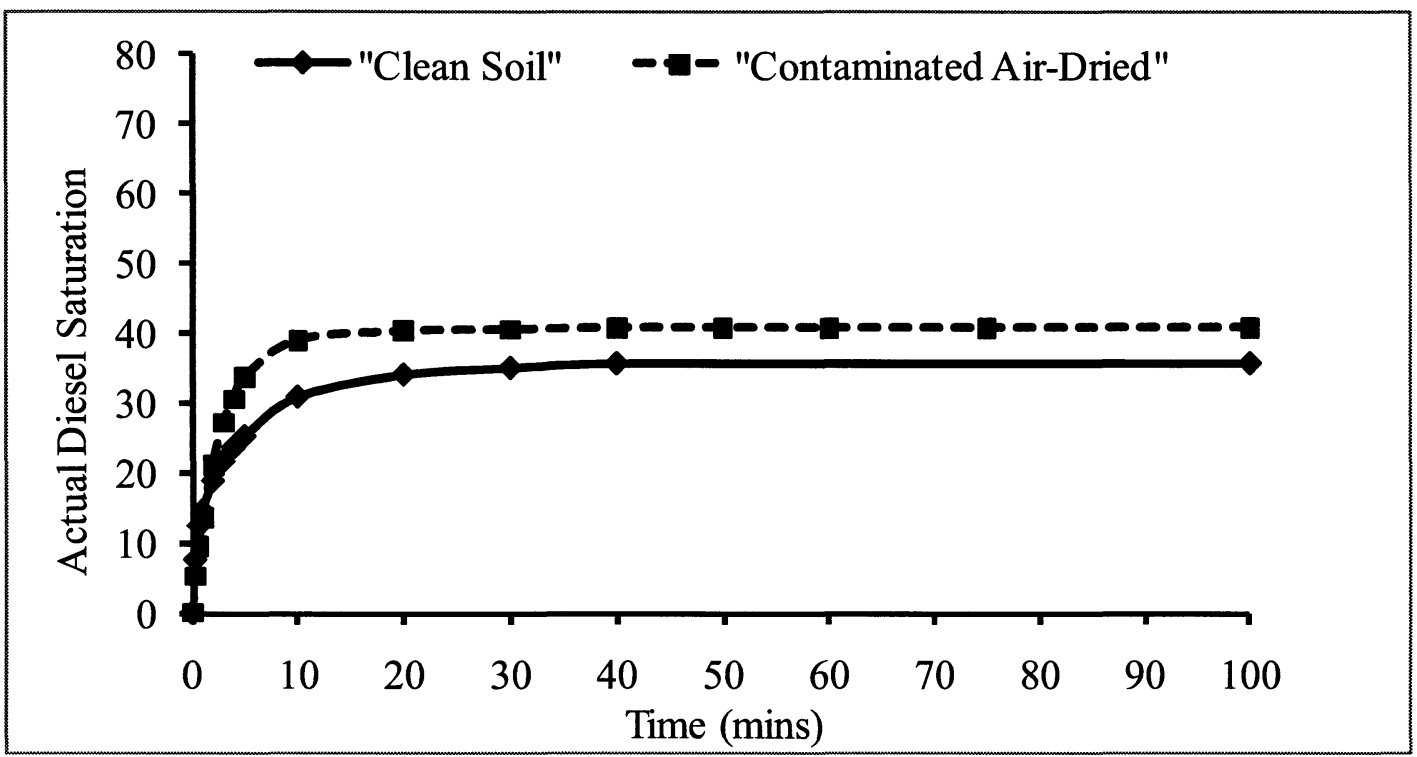

Figure 4.4: Diesel Imbibition Rate in Air-Dried Clean and Air-Dried Contaminated Soil Samples.

Comparing the results of the air-dried clean soil with air-dried contaminated soil clearly indicated that the wettability of the air-dried contaminated soil has been altered. Wettability alteration seen from the imbibition rate tests conducted for air-dried clean soil and air-dried contaminated soil was consistent with the results obtained from the visual observation test and from two-phase (water-diesel) capillary pressure-saturation $\left(P_{c^{-}} S\right)$ experiments for air-dried clean and air-dried contaminated soil samples, illustrated in the following section.

\section{5 $P_{c}-S$ Experimental Results}

Results from the $P_{c}-S$ experiments of the clean soil were compared with results of the contaminated soil for both air-dried and wet or as received conditions. Static two phase (water-diesel) $P_{c}-S$ relationships were determined using the pressure cells as described in sections 3.2.3.a and 3.2.3.b. $P_{c}-S$ relationships were assessed to compare air- 
dried clean and air-dried contaminated soil samples using the setup described in section 3.2.3.a, whereas, $P_{c}-S$ relationships for initially wet clean and initially wet contaminated soil samples were done following the setup described in section 3.2.3.b.

\subsection{1. $P_{c}-S$ Results for Air-Dried Soils}

Results of two-phase $P_{c}-S$ experiments for air-dried clean and air-dried contaminated soil samples are provided in Figures 4.5 and 4.6. Figure 4.5 presents the main drainage pathway, while Figure 4.6 presents the main wetting pathway. Capillary pressure head, expressed as cm of water column, data was plotted versus actual water saturation. As illustrated in section 3.2.3.a, air-dried soil samples were flushed with $\mathrm{CO}_{2}$ to achieve 100 percent initial water saturation within the soil before conducting the experiment. Both soil samples started at initial water saturation of unity and as capillary pressure increased, the degree of water saturation decreased. 


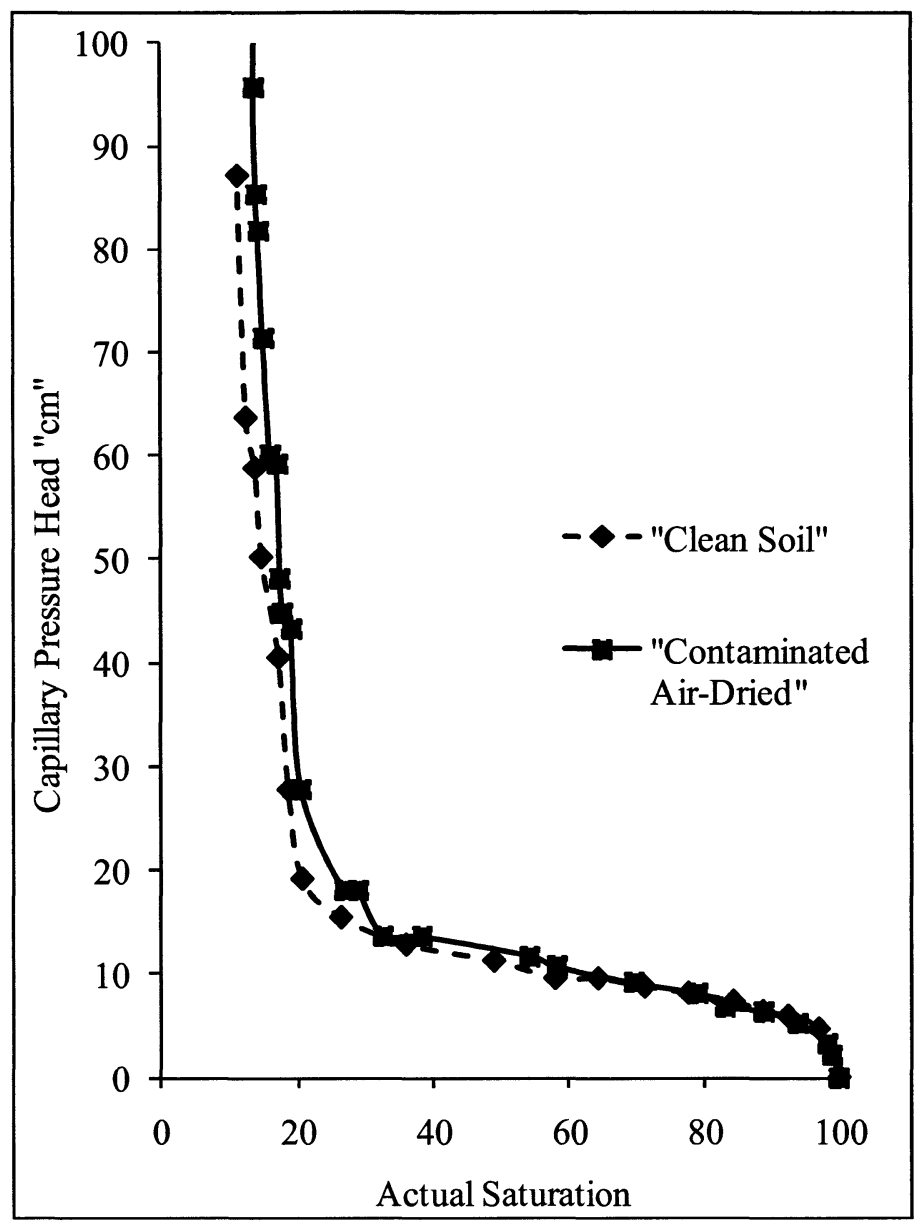

Figure 4.5: Main Drainage $P_{c}-S$ relationships of Air-Dried Clean and Air-Dried

\section{Contaminated Soil Samples.}

Water drainage pathway for both air-dried clean and air-dried contaminated soils exhibited similar behaviour; water was allowed to drain from the water-filled pores almost with the same rate. No variations appeared along the drainage pathways for the air-dried clean soil when compared to the air-dried contaminated soil. The same observed behaviour was attributed to the fact that the system was forced to start at 100 percent initial saturation. Given an initial saturation of 100 percent, one may not see the wettability variation effects on the main drainage pathway (Morrow, 1975). Upon reaching the irreducible water saturation, the experimental procedure was reversed to 
generate the wetting pathway. No variations appeared upon comparison of both wetting pathways for the air-dried clean and air-dried contaminated soil until the capillary pressure approached zero. Figure 4.6 shows the main wetting pathway for both air-dried clean and air-dried contaminated soil types. Greater entrapped diesel saturation was achieved within the air-dried contaminated soil in comparison to the air-dried clean soil. Values of irreducible water saturation, maximum capillary pressure and entrapped diesel saturation (at zero capillary pressure) of air-dried clean and air-dried contaminated soil samples are presented in Table 4.7. Different entrapped diesel saturations were observed in the three experiments conducted for soil types to assess the wettability difference between the air-dried clean and air-dried contaminated soil.

The study by O'Carroll et al. (2005) and Bradford and Leij (1995) for fractionally wet media indicated that as the conditions varied from water-wet to NAPL-wet, the $P_{c}-S$ curve shifted downward. This was not observed for the air-dried contaminated soil assessed in this study. The visual observation test and imbibition rate test indicated changes in wettability, however, the $P_{c}-S$ curve did not shift downwards as observed by the previous studies. 


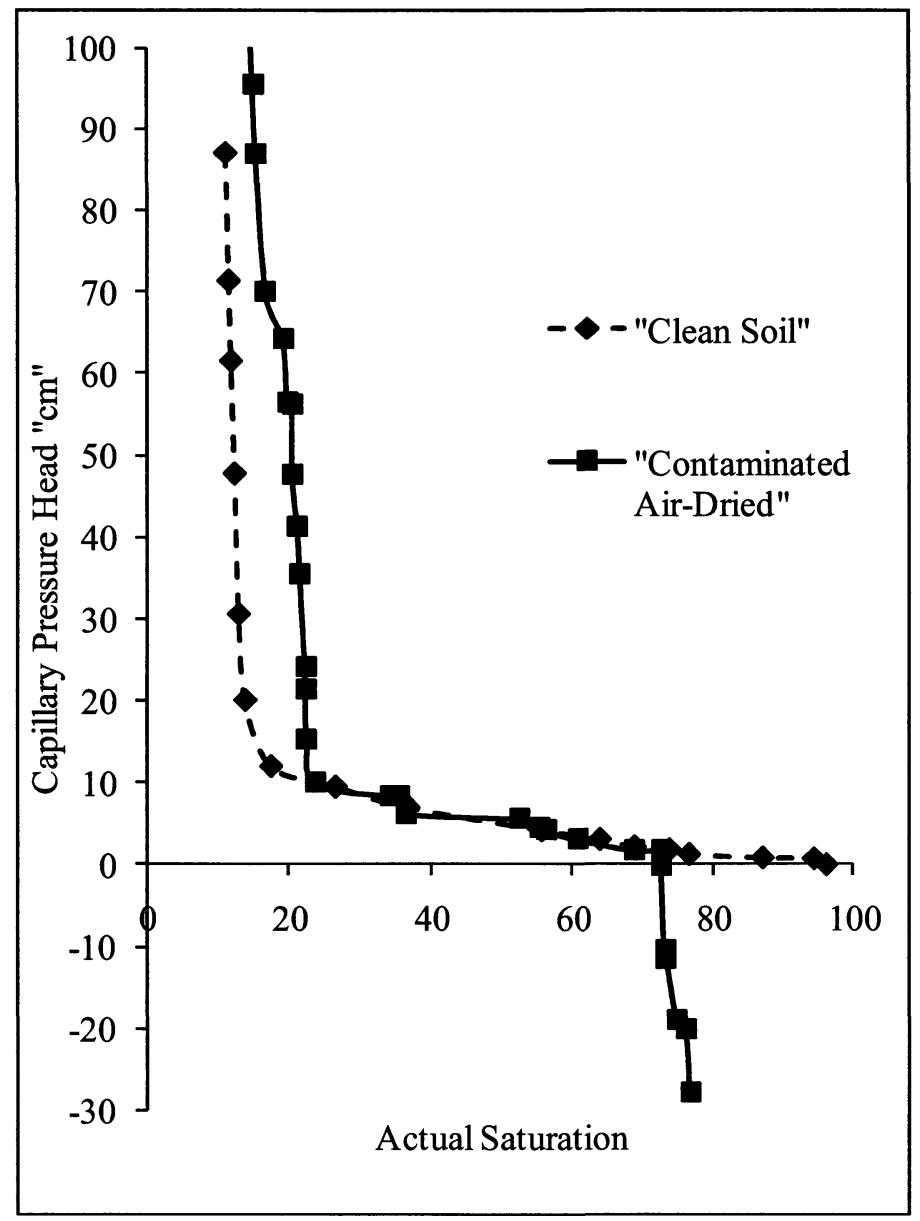

Figure 4.6: Main Wetting $P_{c}-S$ relationships of Air-Dried Clean and Air-Dried Contaminated Soil Samples. 
Table 4.7: Parameters Resulted from $P_{\mathbf{c}}-\mathrm{S}$ relationships Conducted for Air-Dried

Clean and Air-Dried Contaminated Soil Samples.

\begin{tabular}{|c|c|c|c|c|c|c|}
\cline { 2 - 7 } \multicolumn{1}{c|}{} & \multicolumn{3}{c|}{ Air-Dried Clean } & \multicolumn{3}{c|}{ Air-Dried Contaminated } \\
\cline { 2 - 7 } \multicolumn{1}{c|}{} & Test (1) & Test (2) & Test (3) & Test (1) & Test (2) & Test (3) \\
\hline $\begin{array}{c}\text { Irreducible } \\
\text { Saturation } \\
\left(S_{\text {irr }}\right)\end{array}$ & 11.13 & 14.85 & 13.41 & 13.67 & 14.00 & 13.00 \\
\hline Maximum $\mathbf{P}_{\mathrm{c}}$ & 87 & 85 & 78 & 95 & 110 & 137 \\
\hline $\begin{array}{c}\text { Entrapped } \\
\text { Saturation } \\
\left(S_{\text {ent }}\right)\end{array}$ & 4.00 & 7.00 & 10.00 & 35.00 & 26.00 & 25.00 \\
\hline
\end{tabular}

In this work, similar drainage and wetting pathways of the $P_{c}-S$ relationship were observed for both soils, however, the greater entrapped diesel saturation that resulted within the air-dried contaminated soil indicates a change in wettability between the two tested soils. This behaviour indicated that the wettability of the air-dried contaminated soil may have been altered making it more difficult to displace the diesel creating a larger entrapped saturation.

This hypothesis of altered wettability between air-dried clean and air-dried contaminated soil towards intermediate- to NAPL-wetting preferences was raised through differences observed through the wetting pathway of the $P_{c}-S$ relationship and earlier through the visual observation, section 4.3 and the imbibition rate test, section 4.4 . In the visual observation test to assess wettability variations between the air-dried clean and the air-dried contaminated soil, different behaviours were observed upon the interaction of water with the soil medium (Figure 4.2). Also water and diesel imbibition rate tests indicated change in wettability between the air-dried clean soil and the air-dried 
contaminated soil (Figures 4.3 and 4.4). This is consistent with the higher entrapped diesel saturation within the air-dried contaminated soil.

\subsection{2. $P_{c}-S$ Results for Initially Wet Soils}

Based on the observations seen for the air-dried contaminated soil, it was hypothesized that the wettability changes may have occurred due to drying the soil; water that was initially coating the soil gains was removed which allowed the heavier hydrocarbons and additives in the diesel to directly contact and sorb to the soil particle surface. It was questioned as to whether the air-drying of the soil produced or resulted in this change. To address that, $P_{c}-S$ experiments were conducted using the as received contaminated soil, with fines removed, to be able to compare the results to the air-dried contaminated soil. Hence, the wet contaminated soil had to be sieved through sieve number 100 to remove the fines fraction. To sieve the wet contaminated soil, water equilibrated with diesel was used to assist in passing the fines fraction through sieve number 100 . Water equilibrated with diesel was used to prevent or limit the removal of diesel from the wet contaminated soil.

Preliminary $P_{c}-S$ experiments of the initially wet contaminated soil sieved through sieve number 100 (without fines) resulted in inconsistent results compared to clean soil. Similar $P_{c^{-}} S$ relationships were observed between air-dried clean and initially wet contaminated soil when comparing a series of five experiments (figures not shown). That similarity contradicted the variations that were expected to occur, especially with the observed variations that occurred between air-dried clean and air-dried contaminated soil. It was hypothesized that using water equilibrated with diesel to remove the fines may have impacted the diesel content or concentration. As a result, the fines fraction was left 
in the soil as discussed in section 3.2.3.b. Wet contaminated soil samples were only sieved using sieve number 10 according to Figure 3.10 to remove the coarse fraction. Clean soil samples were sieved using the same set of sieves and used as a benchmark to compare to initially wet contaminated soil $P_{c}-S$ relationships.

To address the potential impact of the fines on the $P_{c}-S$ curve of the clean soil, the air-dried clean soil $P_{c}-S$ experiments (without fines) were compared to initially wet clean soil $P_{c^{-}} S$ experiments (with fines). Figure 4.7 presents the main drainage curve between the air-dried clean and initially wet clean soil samples, while, Figure 4.8 presents the main wetting pathway resulted from using the two different soil packing procedures. 


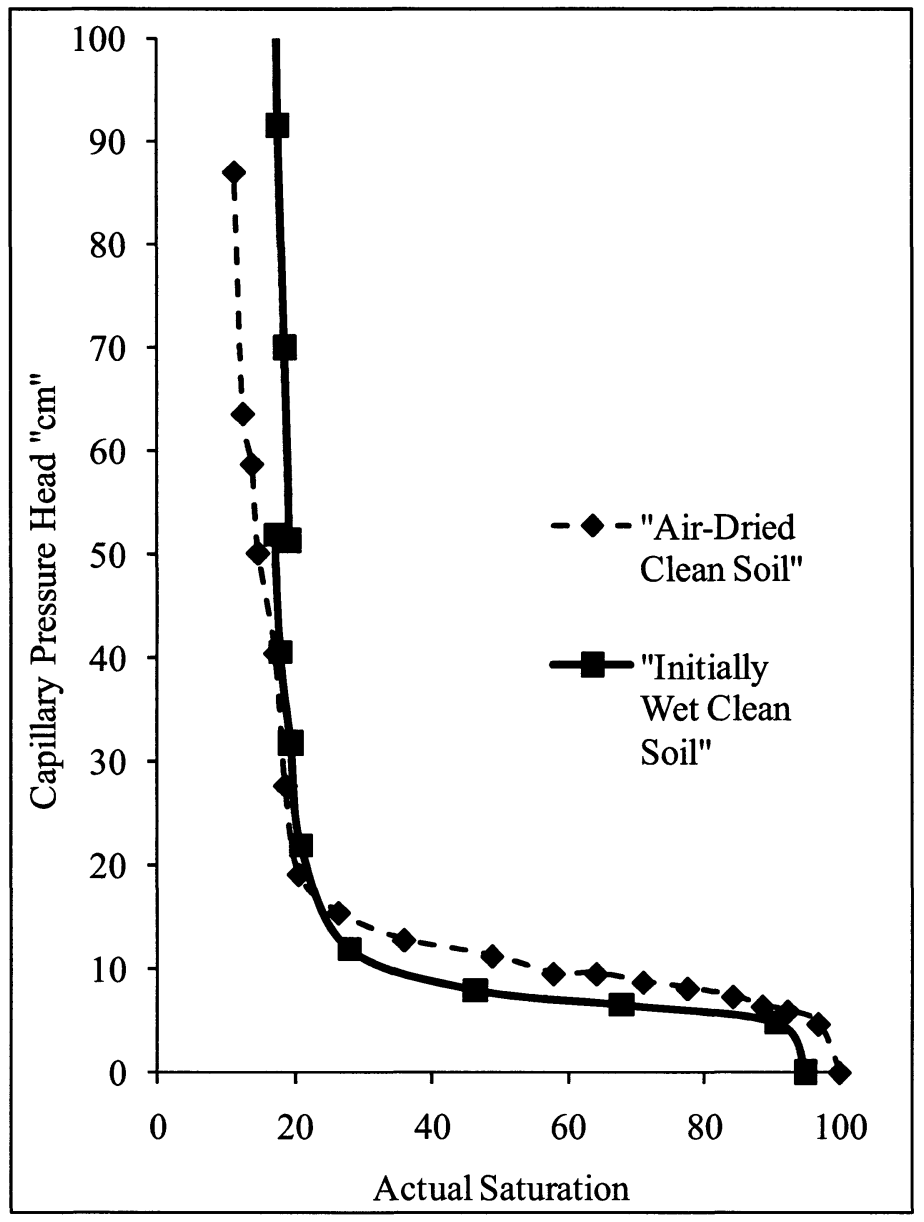

Figure 4.7: Main Drainage $\boldsymbol{P}_{c}-S$ relationships of Air-Dried Clean and Initially Wet Clean Soil Samples.

Main drainage and main wetting pathways of the air-dried clean and initially wet clean soils were close to each other with slightly equal average values of irreducible water saturation and entrapped diesel saturation. It was expected that due to the presence of the fines, the $P_{c}-S$ relationship would shift upward. This was not observed and hence one may conclude that the fines had little impact on the $P_{c}-S$ relationship. 


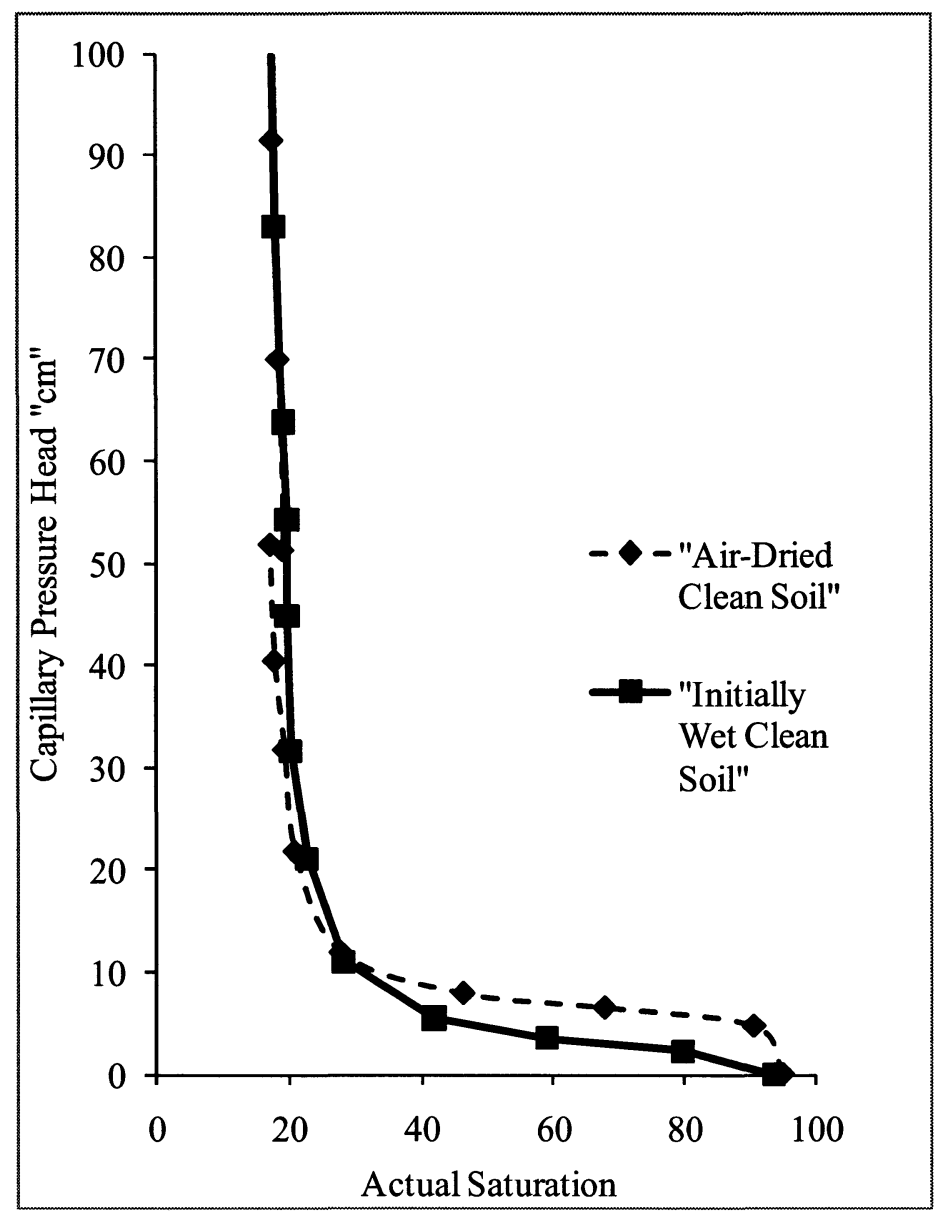

Figure 4.8: Main Wetting $\boldsymbol{P}_{c}-S$ relationships of Air-Dried Clean and Initially Wet Clean Soil Samples.

A set of two $P_{c}-S$ experiments were conducted for the initially wet clean and initially wet contaminated soil types with the presence of fines. Table 4.8 shows the parameters that resulted from conducting two $P_{c}-S$ experiments on each soil type. Different initial water saturation, irreducible water saturation, and entrapped diesel saturation were observed. Figure 4.9 presents the main drainage pathway for one $P_{c}-S$ relationship for each soil type, while, Figure 4.10 presents the main wetting pathway. Capillary pressure head was plotted versus actual water saturation. 
Table 4.8: Parameters Resulted from $P_{c}-S$ relationships Conducted for Initially

Wet Clean and Initially Wet Contaminated Soil Samples.

\begin{tabular}{|c|c|c|c|c|}
\cline { 2 - 5 } \multicolumn{1}{c|}{} & \multicolumn{2}{c|}{ Initially Wet Clean } & \multicolumn{2}{|c|}{ Initially Wet Contaminated } \\
\cline { 2 - 5 } & Test (1) & Test (2) & Test (1) & Test (2) \\
\hline $\begin{array}{c}\text { Initial } \\
\text { Saturation } \\
\left(\text { S }_{\text {int }}\right)\end{array}$ & 95.00 & 85.00 & 95.00 & 75.00 \\
\hline $\begin{array}{c}\text { Irreducible } \\
\text { Saturation } \\
\left(S_{\text {irr }}\right)\end{array}$ & 17.27 & 15.30 & 40.40 & 21.70 \\
\hline Maximum $\mathbf{P}_{\mathbf{c}}$ & 106 & 108 & 180 & 140 \\
\hline $\begin{array}{c}\text { Entrapped } \\
\text { Saturation } \\
\left(\mathbf{S}_{\text {ent }}\right)\end{array}$ & 6.36 & 9.00 & 25.64 & 33.00 \\
\hline \multicolumn{2}{|c|}{} & & & \\
\hline
\end{tabular}

Water drainage pathway for both initially wet clean and initially wet contaminated soil failed to start at a hundred percent initial water saturation as noted earlier. A totally different water drainage pathway was observed for the wet contaminated soil compared to the clean soil. The shape of the relationship was even different than the air-dried contaminated soil, referring to Figure 4.5. Water drained to a lesser degree compared to clean soil resulting in higher than expected irreducible water saturation even at higher capillary pressures than the clean soil. 


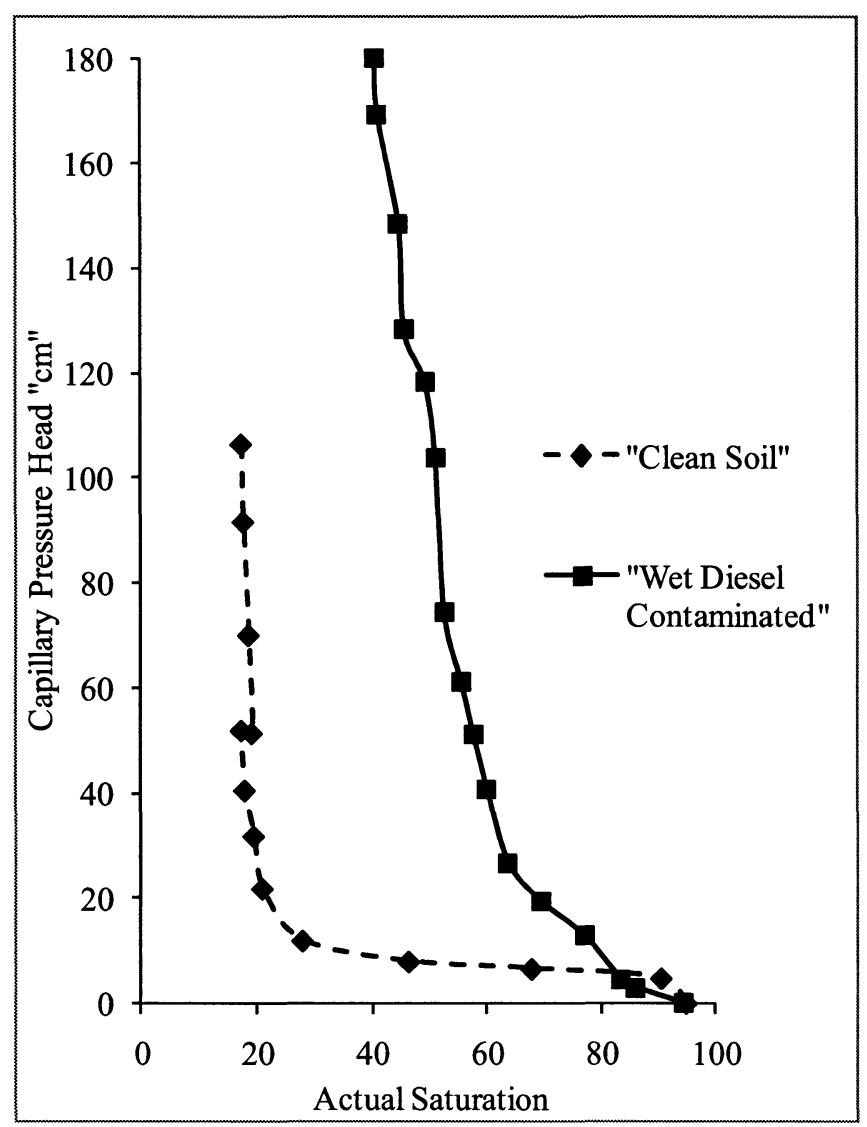

Figure 4.9: Main Drainage $P_{c}-S$ relationships of Initially Wet Clean and Initially Wet Contaminated Soil Samples.

The wetting pathway of the clean soil followed the expected path in terms of the shape taken and the entrapped diesel within the soil at zero capillary pressure, comparing to Figures 4.6 and 4.8. The wetting pathway of the contaminated soil experienced a totally different path than the path followed by clean or by air-dried contaminated soil. 


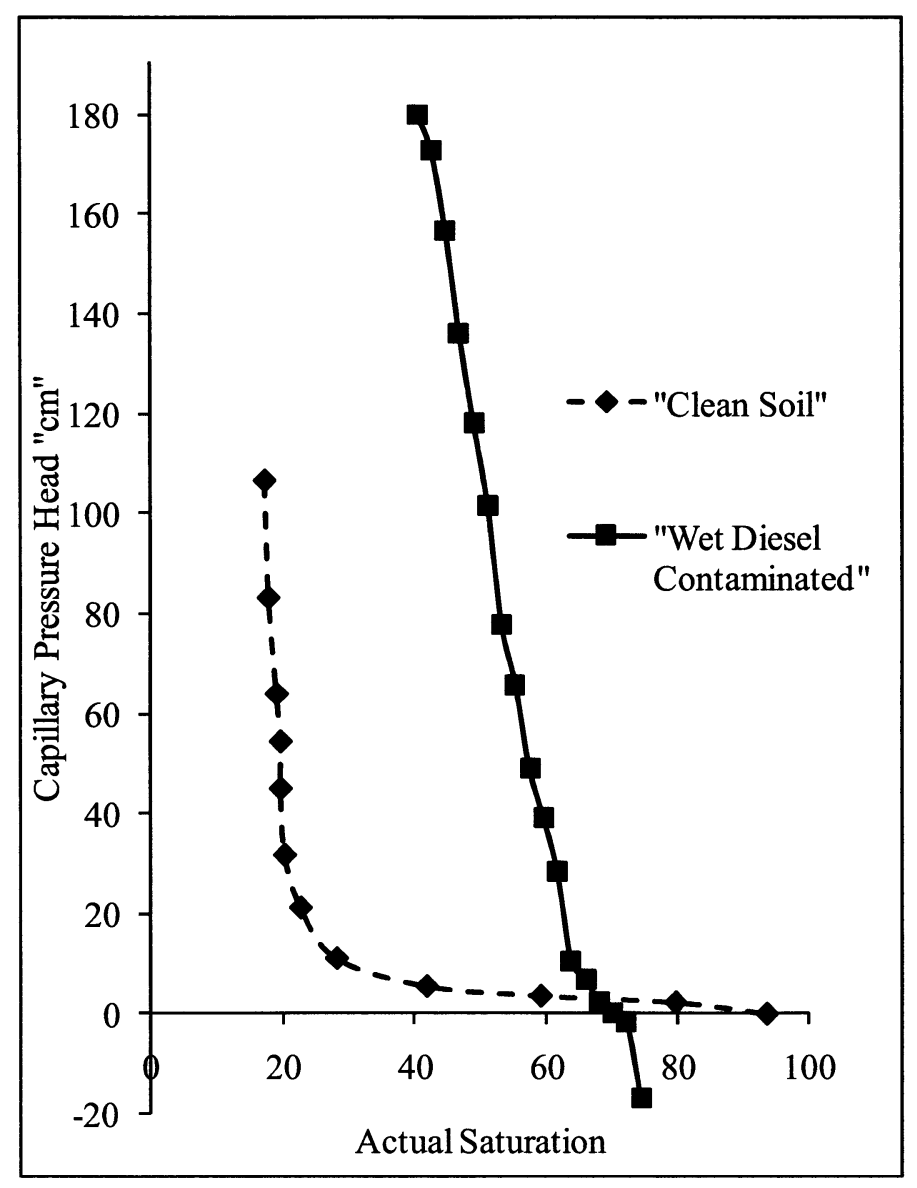

Figure 4.10: Main Wetting $P_{c}-S$ relationships of Initially Wet Clean and Initially

Wet Contaminated Soil Samples.

As mentioned earlier, the preliminary $P_{c}-S$ experiments were conducted on the initially wet contaminated soil sieved to remove the fines and inconsistent results were obtained. As a result, the alternative of maintaining the fines fraction within the soil was introduced to keep the soil as it was received (i.e. no washing with water equilibrated with diesel) and $P_{c}-S$ experiments were conducted for the initially wet contaminated soil and initially wet clean soil, to serve as a benchmark.

As shown in Figures 4.9 and 4.10, after conducting another set of experiments for the initially wet clean soil and the initially wet contaminated soil with the presence of 
fines, totally different relationships were observed for the initially wet contaminated soil compared to the initially wet clean or even air-dried clean soil and air-dried contaminated soil. The main difference was the presence of the fines fraction. The presence of the fines within the initially wet contaminated soil influenced the $P_{c^{-}} S$ relationship even though the same fraction of fines was present in the initially wet clean soil. As a result, further investigation was needed to address and understand the influence of the presence of fines and the mechanisms or facts that are accompanied with that presence.

The potential for changes in wettability of the subsurface soil and its effects on the $P_{c}-S$ relationships were noted and presented through a number of experimental studies (e.g. Fatt and Klikoff, 1959; O'Carroll et al., 2005; Bradford and Leij, 1995). However, Anderson (1987) through his wettability survey, part four titled "effects of wettability on capillary pressure", referenced some work related to the presence of NAPL-wet treated fines and how they can totally influence the $P_{c^{-}} S$ relationship. Fatt and Klikoff (1959) showed the effects of fractional wettability on the $P_{c}-S$ relationship and the shifting downward of the relationship was observed as the NAPL-wet soil fraction increased. Figure 4.11 presents soil media with varied fractional wettability fractions. As shown in the figure, two soil types were examined with the variation of the NAPL-wet soil fraction. Continuous lines represent soil with wider grain size distribution than the dotted lines, resulting in higher $P_{c}-S$ relationship. Numbers on curves represent the NAPL-wet fraction existing within each soil sample. Ottawa Sand was used as the porous medium in their study and the NAPL-wet treated sand was obtained by subjecting sand to organosilane vapours. Note that as the NAPL-wet soil fraction increased, the entire $P_{c^{-}} S$ relationship was shifted downward while maintaining the shape of the relationship, for 
the same grain size distribution. Similar results were presented by Bradford and Leij (1995) and O'Carroll et al. (2005).

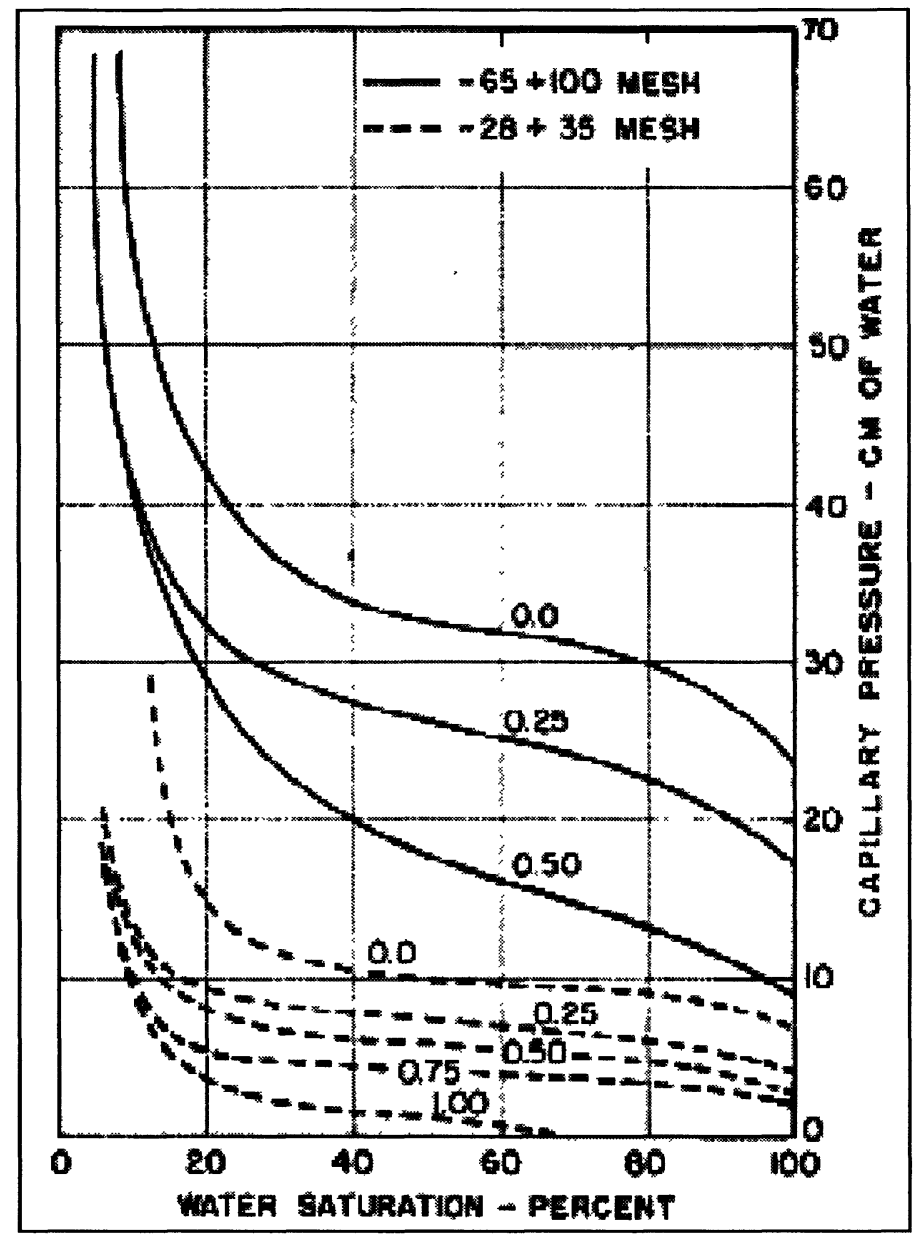

Figure 4.11: Effects of Fractional Wettability on Different Soil Media. (Taken

From Fatt and Klikoff, 1959)

Fatt and Klikoff (1959) also illustrated the effects of fines on the $P_{c}-S$ relationship. After understanding the effects of fractional wettability on the $P_{c}-S$ relationship, they further investigated the effects of treating only the fines fraction within the soil and determining their impact on the $P_{c^{-}} S$ relationships. Figure 4.12 presents the effects of fractional wettability on the $P_{c}-S$ relationship by comparing $P_{c}-S$ curves of three soils; a water-wet soil, a soil with $50 \%$ of the soil grains treated to be NAPL-wet, and a 
soil with the fine fraction treated to be NAPL-wet (labelled FINES TREATED) in which only soil grains that passed through sieve 65-Tyler mesh (ASTM \# 70) were treated and rendered NAPL-wet. The fines fraction compromised $58 \mathrm{wt} \%$ of soil sample. Totally different behaviour was observed for the fines treated curve compared to treating a fraction of all the grain sizes.

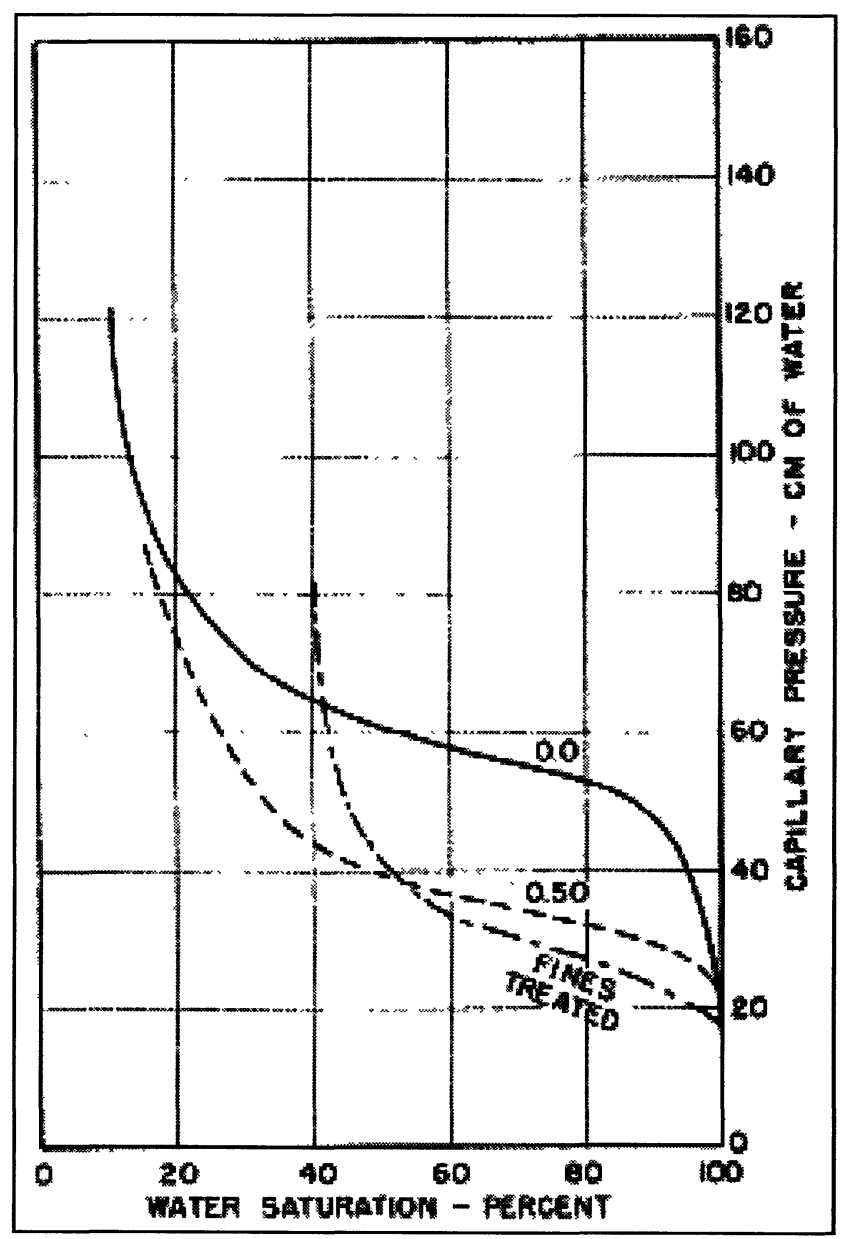

Figure 4.12: Effects of Treating the Fines Fraction on the $\boldsymbol{P}_{c}-S$ relationship. (Taken From Fatt and Klikoff, 1959)

As noted, the fines fraction in the work presented by Fatt and Klikoff (1959) compromised a total of $58 \mathrm{wt} \%$ of soil and significant differences appeared in the $P_{c}-S$ relationships when comparing to treating $50 \mathrm{wt} \%$ of all grain sizes. The $\mathrm{wt} \%$ of NAPL- 
wet treated sand within the two fractions were close to each other, however, major differences were observed between the two $P_{c}-S$ relationships. In their work, the curve marked "FINES TREATED" was below the water wet and the $50 \mathrm{wt} \%$ treated sand curves at low capillary pressures. As capillary pressure increased higher irreducible water saturation was observed when comparing the $P_{c}-S$ relationships for the fines treated and $50 \mathrm{wt} \%$ soils.

In this work, the fines fraction within the soil was not as high as in Fatt and Klikoff's (1959) work. Fines fraction in this study compromised a total $7.5 \mathrm{wt} \%$ of the soil, refer to Table 4.1, compared to $58 \mathrm{wt} \%$ in their work. However, similar behaviour was observed for the initially wet contaminated soil used in this study when compared to clean soil samples. In their work, the treated sand was rendered to NAPL-wet using organosilane, whereas, in this study it could be hypothesized that the diesel had altered the wettability of the fines fraction.

Anderson (1987) referenced similar studies (Luffel and Randall, 1960; Ruhl, et al., 1963; and Schmid, 1964) which addressed the impact of NAPL-wet fines and how they can influence the $P_{c}-S$ relationships. Comparisons between soil cores with native wettability state and after cleaning were presented and different $P_{c}-S$ relationships were observed depending on the soil state. Greater irreducible water saturation was also observed through the previous mentioned studies when conducting $P_{c^{-}} S$ experiments on native state and comparing to after cleaning.

Anderson (1986) through his wettability survey, part one titled "rock/oil/brine interactions and the effects of core handling on wettability", referenced some work related to the adsorption of heavier hydrocarbons onto clays. They have noted the rapid 
adsorption of some compounds onto clays leading to the formation of irreversible bond at the clay surface that may cause the clay surface to be intermediate-wet or NAPL-wet. Clay particles due to their net negative charge have the potential to attract polar compounds which are positively charged causing the adsorption of polar compounds and making the surface NAPL-wet. In this study, the fines fraction consisted of particles with diameters less than $0.075 \mathrm{~mm}$ and the mineralogy of the fine fraction was not determined.

If the fines fraction within the wet contaminated soil was altered to NAPL-wet, based on the previous discussions, then water will remain trapped within the NAPL-wet fines pore matrix due to the snap off and by passing mechanisms which will lead to the loss of the hydraulic conductivity even when applying high capillary pressures. That in turn will influence the $P_{c}-S$ relationships in terms of higher than expected irreducible water saturation (Morrow 1969). 


\section{Chapter 5. SUMMARY AND CONCLUSIONS}

\subsection{Summary}

The objective of the research was to investigate the wettability characteristics of field soils and NAPLs with a goal to better understand the impacts of soil wettability on the constitutive relationships used to simulate the movement, distribution, and remediation of NAPLs at NAPL-impacted sites. Field soil samples were collected at a former truck stop where leakage had occurred from underground storage tanks used to store diesel. Contaminated soil samples were collected below one of the leaking tanks, whereas, clean soil samples that were not directly impacted by diesel were collected from a location beside the tank. Diesel-impacted soil samples were then divided into two categories: air-dried and initially wet or as received. Air-dried samples were needed for the wettability tests; however, during the course of this research it was hypothesized that drying the soil may cause or enhance the potential changes in wettability. Therefore, certain tests were redone using the wet or as received soil. Diesel was purchased at a local station and used throughout the study as no free product was recovered at the site. Physical and chemical properties of the soil and diesel were examined before conducting wettability tests (section 4.1).

Visual observation, imbibition rate tests, and a series of two-phase (water-diesel) $P_{c^{-}} S$ experiments were conducted to investigate the wetting variations between the clean and diesel-impacted soil samples. Visual observation tests and imbibition rate tests were undertaken to assess the wettability difference between the air-dried clean and air-dried contaminated soil samples, whereas, $P_{c^{-}} S$ experiments were conducted on the air-dried 
clean, air-dried contaminated, and on the as received clean and contaminated soils. $P_{c}-S$ experiments can be conducted on initially dry soils as well as initially wet soils, however, it is difficult to achieve $100 \%$ initial water saturation for the wet or as received soil.

Visual observation tests conducted on air-dried clean and air-dried contaminated soils indicated a change in the wettability between the two soils. Water was immediately drawn into the air-dried clean soil, whereas, it remained as a droplet on the top of the airdried contaminated soil. A trial to investigate the reason behind changes in wettability was undertaken by subjecting clean soil to fresh diesel for 30 days and then conducting another visual observation test. Thirty days exposure to fresh diesel did not alter the wettability of the clean soil and it remained water-wet (section 4.3). Results indicated that the changes observed in wettability occurred due to the prolonged exposure to diesel and that the 30 days was an insufficient period to cause changes or that the additives in the purchased diesel from a local station and used in the research were different from those found in the field diesel. In addition, the environmental conditions in the lab may not have reflected the proper conditions that occurred at the field during the prolonged exposure.

Water imbibition rate tests also indicated wettability differences between the airdried clean and air-dried contaminated soil in terms of the rate and amount of water that spontaneously imbibed into the soil. The air-dried clean soil allowed approximately three times the volume of water to be drawn into the soil compared to the air-dried contaminated soil. Imbibition rate test was repeated using diesel. The volumes of diesel drawn into the air-dried clean and air-dried contaminated soils were similar; however, a slightly greater volume of diesel was drawn into the contaminated soil. As a result, the 
air-dried contaminated soil appeared to be less wetting to water and more wetting to diesel compared to the air-dried clean soil (section 4.4).

Differences in the $P_{c}-S$ relationships were observed between the air-dried clean and air-dried contaminated soil (without fines) in terms of the amount of entrapped diesel within the soil at the end of the wetting pathway; at zero $P_{c}$ (section 4.5.1). However, the $P_{c^{-}} S$ did not shift downward as observed in the fractional wettability studies presented by Bradford and Leij (1995) and Fatt and Klikoff (1959).

To assess whether drying the soil may have impacted the wettability, $P_{c}-S$ relationships were conducted using the wet or as received soils. For the previous tests the fines fraction was removed, however, it is difficult to remove the fines fraction from a wet sample. Hence, the $P_{c}-S$ experiments were completed for the clean and contaminated as received soils with the fines fraction. The $P_{c}-S$ relationships for the air-dried clean and wet clean or as received soil were very similar; however, the $P_{c}-S$ relationships for the wet clean and wet contaminated or as received were very different. The $P_{c}-S$ relationship for the contaminated soil resulted in a greater irreducible water saturation. This result was similar to data referenced by Anderson (1987). Fatt and Klikoff (1959) demonstrated that if the wettability if the fines fraction is rendered NAPL-wet, different $P_{c}-S$ relationships will result and a greater irreducible water saturation will be achieved as observed in this research. These findings confirm the importance of fines and their potential impact on soil wettability. Further investigation is needed to address and understand the influence of the presence of fines and the mechanisms that impact the wettability of the fines fraction. 


\subsection{Conclusions}

- Researchers and environmental practitioners have noted that soils and NAPLs found at field sites often do not reflect the ideal conditions of strongly water-wet quartz soils and lab grade NAPL used to simulate NAPL migration and distribution in laboratory experiments. For the diesel-impacted field soil studied in this research, the results of visual observation tests, imbibition rate tests and $P_{c}-S$ experiments clearly indicated that the prolonged exposure of the soil to diesel impacted the soil's wettability. It was hypothesized that the altered wettability was likely due to the sorption of heavier hydrocarbons and/or additives to the soil surface of soil particles.

- Comparisons of wettability tests on air-dried soils indicated that wettability alterations had occurred, however, it was hypothesized that the wettability alterations observed in the lab using air-dried soils may be partially attributed to the drying process which removed the water film that coats soil grains and allowed the heavier hydrocarbons and additives to be in direct contact with the soil's outer surface and enhance sorption. It is recommended that caution be used when assessing the wettability of soils collected in the field to ensure that the wettability was not impacted by the removal process and exposure to different environmental conditions during testing, i.e. air drying.

- A comparison of the $P_{c}-S$ results for the wet or as received clean and contaminated soils indicated that the wettability of the fines fraction within the contaminated soil may have been altered causing a large increase in the irreducible water saturation and a change in the shape of the $P_{c}-S$ relationship. 
This observation was consistent with the behaviour observed by Fatt and Klikoff (1959) when they treated only the fines fraction to be NAPL-wet. Results presented here and by Fatt and Klikoff (1959) and by other studies, indicated that the fines fraction within a soil is important to consider when assessing potential wettability alterations.

\subsection{Recommendations for Future Work}

As the main purpose of this study was to address wettability issues associated with real world conditions, diesel-impacted field soils were used throughout the study as the porous medium. Diesel was purchased at a local station because no free product was recovered at the site. The best representative scenario to real world conditions would be the use of soils and NAPLs collected from the site of concern; field soils and NAPLs may have different properties than lab grade ones.

Studying the soil's mineralogy before conducting wettability tests would help to better characterize the type of soil and mineralogy of the particle surfaces which will impact wettability changes. Examining the surface chemistry of the contaminated soil would also be useful in determining the changes that have occurred due to the prolonged exposure to diesel (e.g. confirm the presence of adsorbed hydrocarbons). This analysis would aid in identifying the primary mechanism responsible for the wettability changes.

For the initial stages of this research, the fines fraction was removed with a goal of evaluating the wettability changes of the soil that were observed in the visual observation and imbibition rate tests. However, the $P_{c}-S$ experiments conducted on the wet or as received soils indicated that the fines fraction had an impact on the wettability 
alternation of the soil. Hence, it is recommended that the potential impact of the fines fraction be addressed at the outset of future work in this area.

\section{REFERENCES}

Adamson, A.W., 1997. Physical Chemistry of Surfaces (6th ed.). John Wiley \& Sons, Inc., New York, USA.

Amott, E., 1959. Observations relating to the wettability of porous rock. Trans., AIME Vol. 216, pp. 156-162. (cited in Anderson, 1986)

Anderson, W.G., 1986. Wettability literature survey: Part 1. Rock/oil/brine interactions and the effects of core handling on wettability. Journal of Petroleum Technology. Vol. 38, No. 10, pp. 1125-1144.

Anderson, W.G., 1986. Wettability literature survey: Part 2. Wettability measurement. Journal of Petroleum Technology. Vol. 38, No. 11, pp. 1246-1262.

Anderson, W.G., 1987. Wettability literature survey: Part 4. Effects of wettability on capillary pressure. Journal of Petroleum Technology, Vol. 39, No. 10, pp. 1283-1300.

A.S.T.M. (American Society for Testing and Materials), 1985. Annual Book of ASTM Standards,Section 5 Petroleum Products, Lubricants, and Fossil Fuels. Am. Soc. Test. Mater., Philadelphia,Pa.

Bradford, S.A., Leij, F.J., 1995. Fractional wettability effects on two-fluid and three-fluid capillary pressure- saturation relations. Journal of Contaminant Hydrology, Vol. 20, pp. 89-109. 
Barranco, F. and Dawson., H., 1999. Influence of Aqueous pH on the Interfacial Properties of Coal Tar. Environmental Science and Technology. Vol. 33, No. 10, pp. 1598-1603.

Chen, L., Miller, G.A., and Kibbey, C.G., 2009. Rapid pseudo-static measurement of hysteretic capillary pressure-saturation relationships in unconsolidated porous media. Geotechnical Testing Journal. Vol. 30, No. 6, pp. 1-10.

Denekas, M.O., Mattax, C.C. and Bobek, J.E., 1958. Reservoir rock wettability-its significance and evaluation. AIME Petroleum Transactions. Vol. 213, pp.155-160.

Donaldson, E.C., 2008. Wettability. Alam, Waqi (C Gulf Publishing Company.

Donaldson, E.C., and Crocker, M.E., 1980. Characterization of the crude oil polar compound extract. DOE/BETC/RI-80/5. National Tech. Info. Sm'ce, U.S. Dept. of Commerce, Springfield, VA 22161: 27 (cited in Donaldson, E.C., 2008)

Dwarakanath, D., Jackson, R.E. and Pope, G.A., 2002. Influence of wettability on the recovery of NAPLs from alluvium. Environmental Science and Technology. Vol. 36, pp. 227-231.

Gerhard, J.I. and B.H. Kueper, 2003. Capillary pressure characteristics necessary for simulating DNAPL infiltration, redistribution, and immobilization in saturated porous media. Water Resources Research. Vol. 39, No. 8.

Harrold, G., Goody, D.C., Lerner, D.N., and Leharne, S.A., 2001. Wettability Changes in Trichloroethylene-Contaminated Sandstone. Environmental Science and Technology. Vol. 35, No. 7, pp. 1504-1510. (cited in Ryder and Demond, 2008) 
Fatt, I. and Klikoff, W.A., 1959. Effect of fractional wettability on multiphase flow through porous media. Trans., AIME. Vol, 216, pp. 426-432.

Karickhoff S.W., 1981. Semi-emiprical estimation of sorption of hydrophobic pollutants on natural sediments and soils. Chemosphere. Vol. 10, No.8, pp. 833-846.

Kyte, J.R., Naumann, V.O., and Mattax, C.C., 1961. Effect of reservoir environment on water-oil displacements. Journal of Petroleum Technology. pp.579-582. (cited in Anderson, 1986)

Liu, K., Eadington, P., Coghlan, D., 2003. Fluorescence evidence of polar hydrocarbon interaction on mineral surfaces and implications to alteration of reservoir wettability. Journal of petroleum Science and Engineering. Vol. 39, pp. 275-285.

Luffel, D.L. and Randall, R.V., 1960. Core handling and measurement techniques for obtaining reliable reservoir characteristics. Paper SPE 1642 G presented at the 1960 SPE Formation Evaluation Symposium, Houston, Nov.21-22. (cited in Anderson, 1987)

Molnar, I. L., 2009. The wettability of a DNAPL/surfactant solution on quartz and iron oxide surfaces. M.Sc. Thesis, Western of Western Ontario, London, Ontario, Canada.

Morrow, N.R., 1970. Irreducible wetting-phase saturations in porous media. Chemical Engineering Science. Vol. 25, pp. 1799-1815.

Morrow, N.R., 1975. Effects of surface-roughness on contact angle with special reference to petroleum recovery. Journal of Canadian Petroleum Technology. Vol. 14, No. 4, pp. 42-53. (cited in O'Carroll et al., 2005) 
Morrow, N.R., 1990. Wettability and its effect on oil recovery. Journal of Petroleum Technology. Vol. 42, No. 12, pp. 1476-1484.

O’Carroll, D.M., Abriolab, L.M., Politykac, C. A., Bradford, S. A. and Demonde, A. H., 2005. Prediction of two-phase capillary pressure-saturation relationships in fractional wettability systems. Journal of Contaminant Hydrology. Vol. 77, pp.247-270.

Parker, J.C., Lenhard, R.J., and Kuppusamy, T., 1987. A parametric model for constitutive properties governing multiphase flow in porous media. Water Resources Research. Vol. 23, No. 4, pp. 618-624.

Powers, S. and Tamblin, M. 1995. Wettability of porous media after exposure to synthetic gasolines. Journal of Contaminant Hydrology. Vol 19, No. 2, pp. 105-125.

Powers, S., Anckner, W. and Seacord, T. 1996. Wettability of NAPLcontaminated sands. Journal of Environmental Engineering. Vol. 122, No. 10, pp. 889890.

Ruhl, W., Schmid, C., and Wissmann, W., 1963. Displacement tests with porous rock samples under reservoir conditions. Sixth World Petroleum Conference, Frankfurt, West Germany. (cited in Anderson, 1987)

Ryder, J. and Demond A., 2008. Wettability hysteresis and its implications for DNAPL source zone distribution. Vol. 102, pp. 39-48.

Salehzadeh, A., Demond, A.H., 1999. Pressure cell for measuring capillary pressure relationships of contaminated sands. ASCE Journal of Environmental Engineering. Vol. 125, No. 4, pp. 385-388. 
Schmid, C., 1964. The wettability of petroleum rocks and the results of experiments to study the effects of variations in wettability of core samples. Erdol und Kohle-Erdgas-Petrochemie, Vol. 17, No. 8, pp.605-609. English translation available from the John Crerar Library, Translation No. TT65-12404. (cited in Anderson, 1987)

Treiber, L.E., Archer, D.L., Owens, W.W., 1972. Laboratory evaluation of wettability of 50 oil-producing reservoirs. Society of Petroleum Engineers Journal. Vol. 12, No. 6, pp. 531-540.

Van Geel, P.J. and J.F. Sykes, 1997. The importance of fluid entrapment, saturation hysteresis and residual saturations on the distribution of a lighter-than- water non-aqueous phase liquid in a variably saturated sand medium. Journal of Contaminant Hydrology. Vol. 25, No. 3-4, pp. 249-270.

Zheng, J. and Powers, S., 1999. Organic bases in NAPLs and their impact on wettability. Journal of Contaminant Hydrology. Vol. 39, pp.161-181. 